MANAGERIAL

e-LEARNING PROFESSIONALS

AT THE CORPORATE UNIVERSITY

A Dissertation
presented to
the Faculty of the Graduate School
at the University of Missouri

In Partial Fulfillment

of the Requirements for the Degree

Doctor of Philosophy

by

MATTHEW LIVENGOOD

Dr. Jeni Hart, Dissertation Advisor

December 2020 
The undersigned appointed by the dean of the Graduate School, have examined the dissertation entitled

MANAGERIAL e-LEARNING PROFESSIONALS AT THE CORPORATE UNIVERSITY presented by Matthew Livengood, a candidate for the degree of doctor of philosophy, and hereby certify that, in their opinion, it is worthy of acceptance.

Professor Jeni Hart

Professor Bradley Curs

Professor Casandra Harper Morris

Professor Aimee Klimczak 


\section{DEDICATION}

Dedicated to my dear family and friends who got me through.

Kathy, Kent, Sarah, Adam, Jacob, Bizzie, Brenny, Arianna, Nadine, Tracey, and even Sean.

In loving memory of Ken and Doris Kovach.

They never had their own son but I couldn't have ever wished for better grandparents. 


\section{ACKNOWLEDGEMENTS}

There are so many talented and whip-smart people who helped me get to this point in my academic career. Everyone I mention here, bless you. And thank you.

I first met Dr. Jeni Hart in my professional capacity when she came to MU from Southeast Missouri State University. We walked through Jesse Hall and chatted. I thought "this is a cool woman" and years later, when I considered going back to school for a $\mathrm{PhD}$, I reached out to her for guidance. I had been out of school by that time for 13 years so I was on the fence. Jeni was absolutely supportive and in spite of my fear of taking the GRE again, her support was transformative. And since I started back, I have had highs and lows but she has been considerate, patient, and among the smartest people I know.

Dr. Bradley Curs is a quantitative, numbers guy. Not me. And I was initially intimidated. But Brad likes ideas and robust answers; understanding there are many different ways to examine a problem and solution. That is me. Higher education finance was a quality learning experience and I appreciate Brad wants all his students, regardless of approach, to understand and grow and advance our understanding of higher education as an enterprise.

Dr. Casandra Harper Morris offered a writing course one summer that was absolutely eye opening. Write something and then read it aloud. It was a 4-week course so it was a hustle during a muggy, Missouri June. She approached the course as a team-effort where we would read to one another around a table which reinforced writing is not a solitary effort. Writing is a community activity.

Dr. Aimee Klimczak taught one of my favorite courses during my masters program. She was finishing her $\mathrm{PhD}$ at the time and not only did I learn a lot, we had the best time in class. It was in the fall of, gosh, 1996, and at the time, my husband was an educator in the campus 
women's center. Somehow, what we were doing after class came up and I said I was going to the Take Back the Night March around campus. And she said "take away the night?" so I had to explain it and we had a good laugh about that.

Dr. Molly Nicaise, my masters advisor, was a mentor and really went to bat for me when I was trying to power-through the program in 18 months. One of my thesis committee members, who I didn't really know and had never taken a course from, was very on the fence. But Molly got me through. Moral of that story, have a great advisor and don't have anyone on your committee you don't know.

Mrs. Abrahamson, my $6^{\text {th }}$ grade teacher, was a blessing by helping an awkward, gay kid in the suburbs feel smart and capable of succeeding. She set me up to be successful in junior high and high school. She helped me find a drive to learn and a passion for education.

And lastly, I wanted to mention of few of my fellow students who were absolute bliss to have in class and get me through coursework. Drs. Jonathon "Jolly Gay Giant" Pryor, Giuli Krug, and Kathy Moss. Bright, kind, and genuinely lovely people. Working full-time and then taking classes in the evening was a real challenge and these are among the best people to get you through that gauntlet. 


\section{TABLE OF CONTENTS}

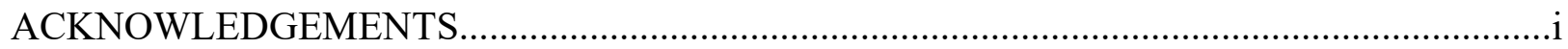

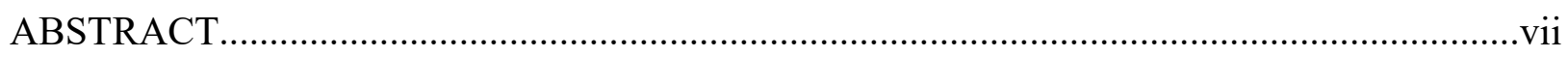

\section{CHAPTERS}

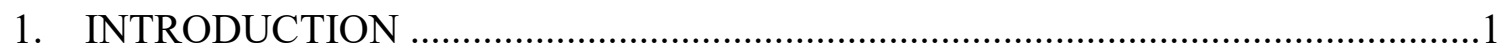

Background of the Problem...........................................................................

Statement of the Problem .................................................................................

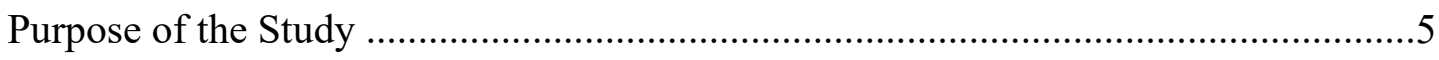

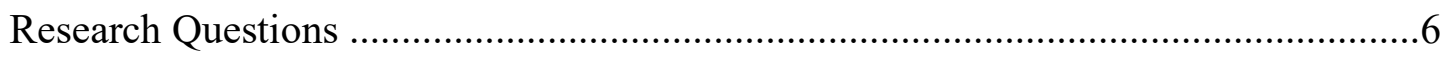

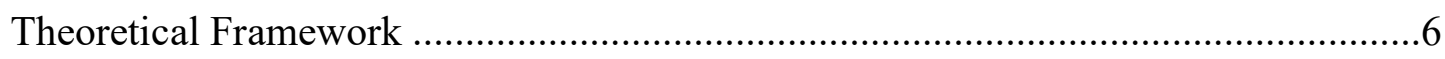

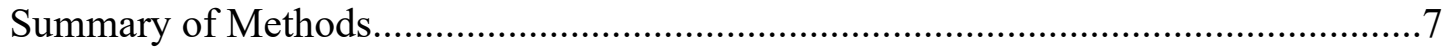

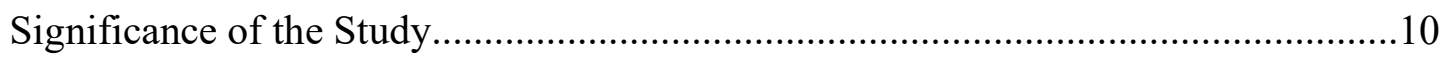

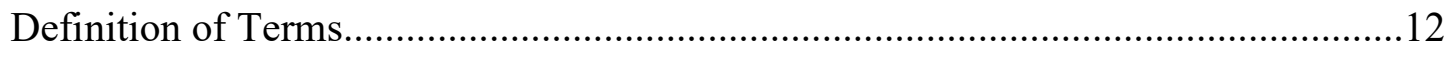

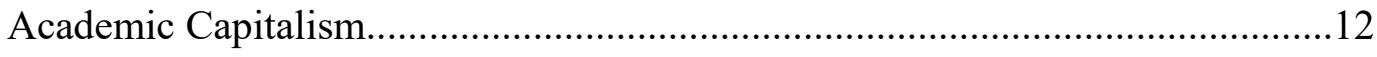

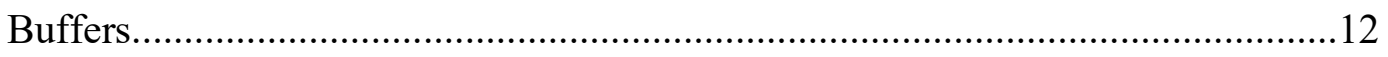

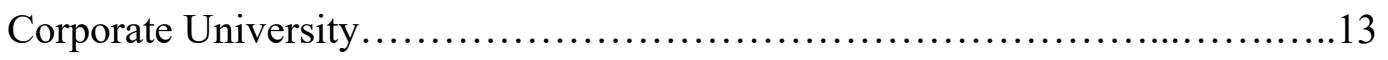

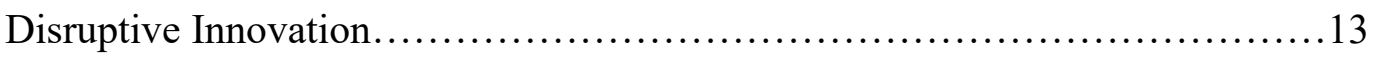

Instructional Designer............................................. 13

Instructional Unbundling ........................................... 13

Managerial Professional............................................... 14

Massification....................................................... 14

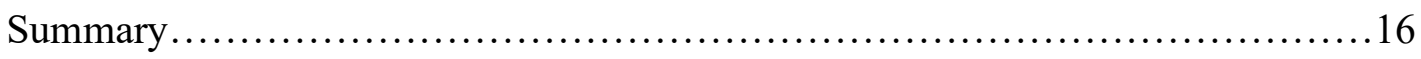

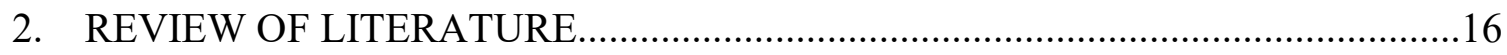


Higher Education as an Academic Capitalist Enterprise...................................... 18

Instructional Unbundling................................................ 19

Faculty as Managed Professionals.......................................21

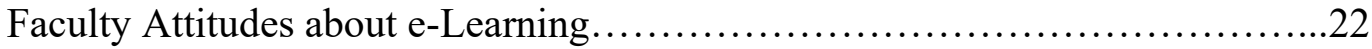

Rise of the Managerial Professional..........................................25

Instructional Designers as Managerial Professionals..........................27

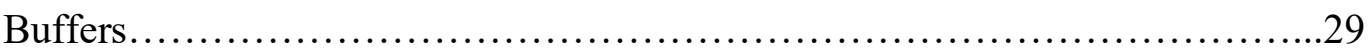

Brokers........................................................ 31

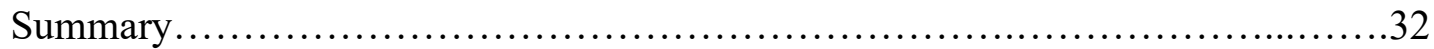

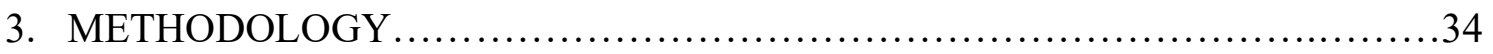

Research Questions....................................................... 34

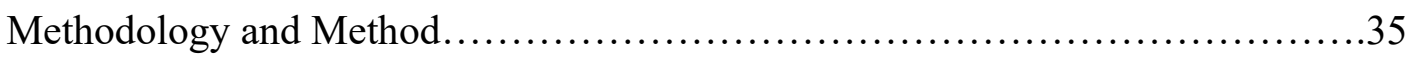

Method................................................................ 36

Participant Selection and Recruitment.................................... 37

Data Collection........................................................ 38

Initial Interviews....................................................... 38

Participant Journaling................................................ 39

Final Interviews....................................................40

Field Notes and Analytic Memos........................................40

Data Analysis........................................................41

Trustworthiness......................................................42

Credibility and Transferability......................................43

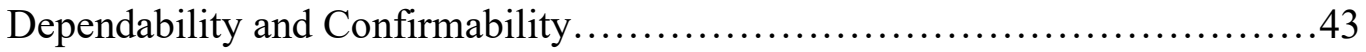


Researcher Role and Positionality ..............................................43

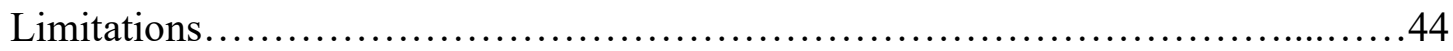

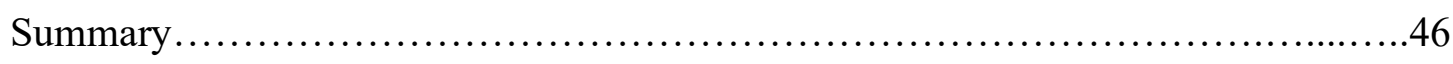

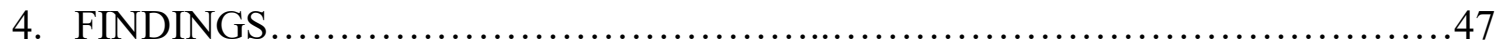

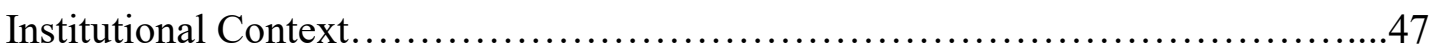

Paths to Instructional Design...............................................50

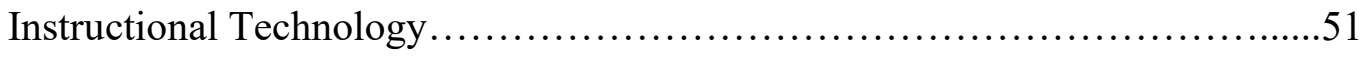

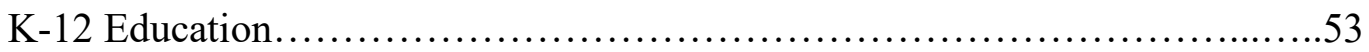

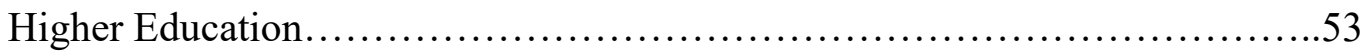

Creating Partnerships with Faculty ............................................55

Developing an Interpersonal Bond with Seasoned Faculty......................56

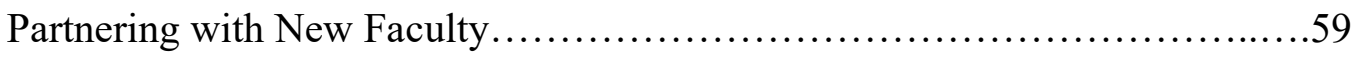

Partnering with Non-tenure Track (NTT) Faculty ...........................60

Barriers to Collaboration...........................................................61

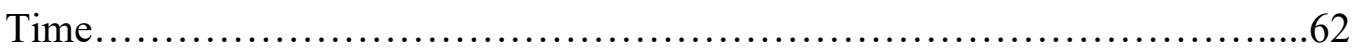

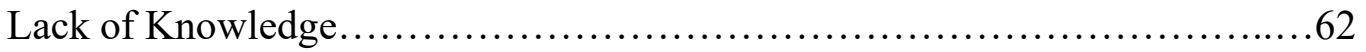

Concerns Over Academic Freedom.............................................64

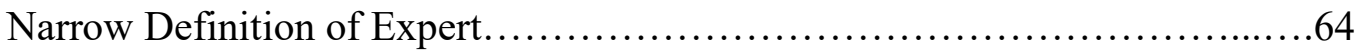

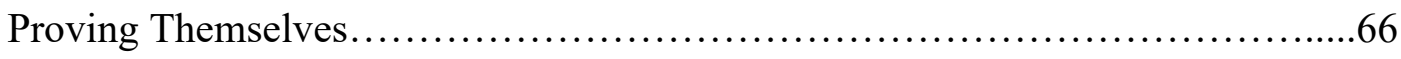

Faculty Development and Training.......................................67

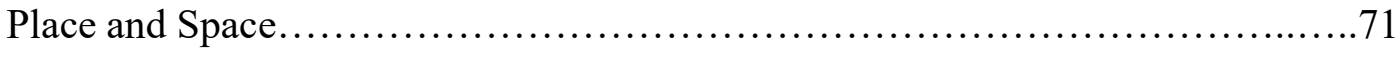

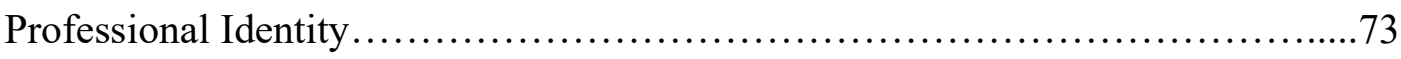

Outreach and Promotion of Services......................................74 
Demonstrating a Breadth of Knowledge and Professionalism. ...

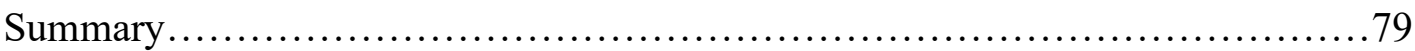

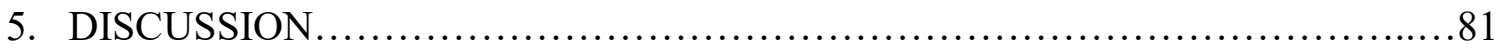

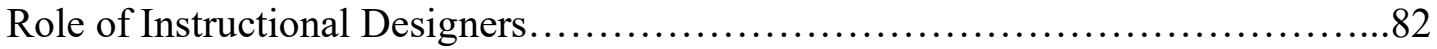

Activities......................................................... 83

Factors Governing Interactions.......................................83

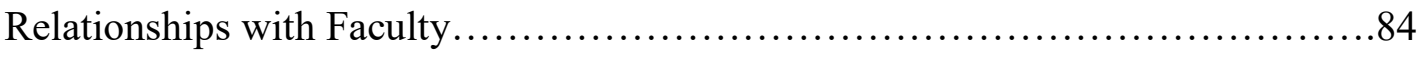

Recommendations for Future Research..................................86

Recommendations for Practice...........................................86

Conclusion......................................................... 87

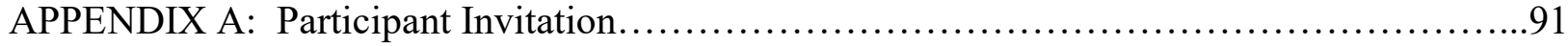

APPENDIC B: Informed Consent............................................. 92

APPENDIX C: Semi-Structured Initial Interview Protocol.............................93

APPENDIX D: Semi-Structured Participant Calendar Annotation Protocol....................94

APPENDIX E: Semi-structured Second Interview Protocol..............................95

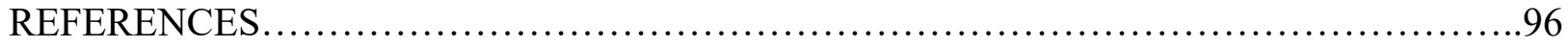

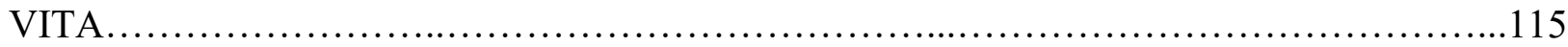




\title{
MANAGERIAL e-LEARNING PROFESSIONALS IN THE CORPORATE UNIVERSITY
}

\author{
Matthew Livengood \\ Dr. Jeni Hart, Dissertation Supervisor
}

\begin{abstract}
This study explores the lived experience of managerial professionals. With the pressures on higher education to generate new revenue streams, specifically the professional life and identity of instructional designers are explored regarding the various pressures of academic capitalism and instructional unbundling through the lens of Activity Theory. Including interviews and annotated calendars/journaling, participants provide insights into the daily life and professional negotiation involved in a changing higher education landscape. Ultimately, professional esteem and respect, as well as trusting relationships between these academic professionals, framed a sense of professional identity.
\end{abstract}




\section{CHAPTER ONE: INTRODUCTION}

"My role is to help you teach well with technology" has been my opening line in meetings with faculty for over 2 decades. Working as an instructional designer, the contours of my relationship with faculty have been difficult to define. I found this line somewhat demystifies my function while conveying my interest in good teaching. I am not a graphic designer, copy editor, computer technician, programmer, meddler, monitor, or coordinator of a "Foucouldian panopticon of surveillance" (Amory, 2013, p. 49), but rather I am an educated professional seeking to help professors enhance their teaching, and student learning, by any means available.

Scholars categorize those in my emergent professional class as managerial professionals (Rhoades, 2007; Slaughter \& Rhoades, 2004); these professionals will be the focus of study. Managerial professionals have become essential to executing entrepreneurial action through the production of quality higher education by working one-on-one with faculty with unique access to, and influence on, curriculum development, which once was the exclusive domain of faculty (Ebert-May, et al., 2011; Rhoades \& Sporn, 2002; Wilson, 2012). My interest in the experiences of managerial professionals in general, and specifically instructional designers, is to more fully understand the ways they negotiate experience and identity in an academic capitalism setting.

\section{Background of the Problem}

The difficulties facing higher education comprise a confluence of complex and overlapping internal and external pressures including decreased direct state allocations to operating budgets; raised performance expectations for students, teachers, and administrators; and an enhanced agenda embracing market-based innovation (Austin, 2002; Brooks \& Miles, 2010; Lewis \& Fisarelli, 2010). Resulting fiscal, social, and cultural pressures on public higher 
education have necessitated innovative and disruptive trends such as corporatization, marketization, managerialism, and accountability (Doyle, 2010; Robst, 2000; Sandeen, 2014; Steck, 2003; Szekeres, 2004; Wood, 2013).

Considering these shifting priorities, Slaughter and Rhoades (2004) developed the theory of academic capitalism to describe further engagement of higher education institutions in the competitive marketplace. Implementation of revenue-generating programs and subsequent implications for academic culture and practice, the epistemological basis for academic capitalism can be synthesized into the concept of disruptive innovation (Christensen, 1997, 2006; Deem, 2001; Olivas, 2004; Wolff, 2010). Disruptive innovations impact competition between institutions, access to new student populations, and changes to the structure and procedures in teaching (Christensen, 1997, 2006).

Academic capitalism and the entrepreneurial university have necessitated new professional roles, such as instructional designer and new approaches, such as instructional unbundling to campus. Instructional unbundling is a disruptive innovation that divides instruction into distinct tasks performed by experts in areas such as instructional design, assessment, and quality improvement (Smith, 2008). To practically implement instructional unbundling, contemporary higher education continues to embrace new and varied interdisciplinary teams of professionals who contribute to instruction by leveraging content experts, instructional designers, editors, and technologist (Fumasoli \& Stensaker, 2013; Hardre \& Chen, 2008; Rhoades, 2001; Sandeen, 2014). Subsequently, multi-professional teams of academic and professional staff are more boundaryless, with overlapping and interrelated outputs (Engeström, 2000, 2004; Whitchurch, 2012; Williams van Rooij, 2011). This proposed study, within the academic capitalism and instructional unbundling contexts, will examine the 
experiences of a newly emergent professional class of managerial professionals: instructional designers.

New forms of instructional delivery (e.g., e-Learning) have been primarily reconceptualized around emerging technology. Specifically, e-Learning is seen to have revolutionized and transformed higher education by expanding college access and better aligning with contemporary workforce demands (Rhoads, Sayil Camacho, Toven-Lindsey, \& Berdan Lozano, 2015). e-Learning has further unbundled traditional faculty instructional practices into multiple, discrete, serially-interdependent actions (Whitchurch, 2012). Perceived contextual factors among faculty, such as public demands for accountability, return on investment, and flexible delivery modalities, "smack of consumer-oriented bias" (Rhoades, 1987, p. 2), the discourse of such sentiments influences the professional identity of instructional designers (Barley, 1996).

To coordinate new, revenue-generating academic programming, the role of academic managerial professionals has emerged in the modern higher education workplace (Rhoades \& Slaughter, 2004; Sandeen, 2014). This sort of managerialism purports a focus on "efficiency, effectiveness, and excellence" (Deem, 2001, p. 10). Managerial professionals such as instructional designers are perceived as advocates for a "virtual assembly line" approach to unbundling and de-centering faculty in the teaching process (Rhoades \& Slaughter, 2004, p. 49). Social positioning and identity development in this context are culturally situated and influence the effectiveness of instructional output and division of labor in contemporary higher education (Daniels, 2007). However, faculty have concerns over this new and growing group of academic professionals (Rhoades \& Slaughter, 2004). Although integrally involved in academic programs, 
these professionals are neither faculty nor administrators, especially academic, but contribute directly to the distribution of instruction, have grown in numbers (Rhoades \& Slaughter, 2004).

New team configurations, a further result of disruptive innovation, have led to hiring practices resulting in a managerial professional class that bridges conventional occupations and categories; they are neither faculty nor administrator although accountable to both (Rhoades \& Slaughter, 1997). Buffer is a positionality term I use to describe managerial professionals who provide assistance, guidance, mentoring, and value to the work of university faculty (Barley, 1996; Rhoades, 2007, 2012). As buffers, managerial professional teams bridge administrative and academic cultures as a "matrix of non-faculty support personnel" (Rhoades, 2007, p. 1), facilitating course content development and delivery. These professionals possess advanced education credentials, belong to professional organizations, and contribute to a highly specialized body of knowledge (e.g., teaching practice, assessment). Further, despite some faculty animosity, "managerial professionals are not 'unproductive' labor but rather central production workers on campus" (Rhoades \& Slaughter, 1997, p. 23). They exist for the professional development of faculty and the production of teaching output.

\section{Statement of the Problem}

Innovative and disruptive trends such as corporatization, marketization, managerialism, accountability, performance-based funding, and instructional quality require managerial professionals to develop models, systems, and structures in universities to impact teaching and learning (Blin \& Munro, 2007; Christensen, 1997, 2006; Sandeen, 2014; Steck, 2003; Szekeres, 2004; Wood, 2013). For organizations to operate successfully, notably where boundaries and responsibilities of faculty, managerial professionals, and administrators have high levels of functional overlap, there becomes a pressing need to negotiate and clarify boundaries and 
responsibilities (Baruch, 2004; Weick, 1976). Further, disruptive innovations in the higher education social system, such as instructional unbundling, impact the tone and tenor of discourse between faculty and institutional administration. In an attempt to centralize and standardize instructional roles, policies, and structures associated with the production of teaching, new a professional class of managerial professionals has emerged (Amaral, 2013; Bratianu \& Stanciu, 2010; Sandeen, 2014; Szekeres, 2006). However, scholarship fails to account for new professional configurations in contemporary institutional settings, notably the managerial professionals who buffer faculty and administrators. I suggest a dearth of research on the role managerial professionals play in the corporate university context offers an incomplete, albeit essential, picture of the evolution of academic capitalism, and its potential implications for teaching and learning.

\section{Purpose of the Study}

Disruptive innovations in higher education are myriad. In this context, disruptive innovations such as instructional unbundling encompass new divisions of labor impacting institutional rules and culture (Blin \& Munro, 2007; Patchen \& Smithenry, 2013). This study proposes to explore the influence of competing pressures and entrepreneurial forces that manifest in disruptive innovations for one group of managerial professionals (Rhoades \& Slaughter, 2004). My analysis will examine perspectives of one higher education constituency of managerial professionals: instructional designers. I suggest examination of instructional designers, who serve as buffer between institutional management and faculty, will provide a more complete picture of the implications of disruptive innovation (Christensen, 1997, 2006; Coates \& Goedegeburre, 2012; Whitchurch, 2012; Williams van Rooij, 2011). 
The principal outcomes of this study are to understand the ways in which instructional designers negotiate their identity in an academic capitalist context and maintain interpersonal relationships with faculty (Blin \& Munro, 2007; Sandeen, 2014; Steck, 2003; Szekeres, 2004; Wood, 2013). Specifically, this study asserts managerial e-Learning professionals' (i.e., instructional designers) positionality in this culture is unique and instructive. These professionals operate as insiders and outsiders in multiple communities. By exploring the professional identity and lived experiences of instructional designers in this context, I will develop a more robust understanding of contemporary higher education including internal and external pressures triggering change and subsequent outcomes for students, faculty, and professional staff.

\section{Research Questions}

Through a qualitative descriptive case study, I intend to address the following research question: How do instructional designers describe their role within the university? Additionally, the following sub question will provide insights into instructional designers' primary working relationship: How do instructional designers describe their relationship with faculty?

\section{Theoretical Framework}

Activity theory will be used to explore the ambiguity, overlapping, and permeable professional interests, and cultural context of higher education through the work of instructional design professionals (Engeström, Engeström, \& Kärkkäinen, 1995). Broadly, activity theory examines human action in a social, or activity, system especially where professional activity spans organization and cultural boundaries (Barab, Evans, \& Baek, 2003; Engeström, 1996; Engeström et al., 1995; Podolny \& Baron, 1997). Activity theory is especially useful in analyzing complex and overlapping roles, processes, values, and cultures (Patchen \& Smithenry, 
2013). Organizational culture, including local structures of belief, hierarchies, stratification, and recurring patterns of activity expose "the intersection of historical, structural, and action contexts, showing how history and 'structure' shape action and how actions (re)produce history and 'structure"' (Hall, 2003, p. 37). By using activity theory, my analysis moves beyond examination of formal structures by closely examining the interconnected relationships between organizations, professions, and individuals (Haedicke, 2012).

Activity theory is characterized by seven specific dimensions: subjects, objects, community, mediating artifacts, rules, division of labor, and outcomes (Engeström, 1999, 2000, 2001). In this study, instructional designers are subjects; instructional design and e-Learning are mediating artifacts; quality instruction (e.g., achieved learning outcomes, satisfied and employable graduates) is the object; higher education customs and policies comprise rules; the various stakeholders engaged in disruptive innovation form the community; and faculty and managerial authority over instructional designers in instructional unbundling determines the division of labor.

The university as activity system is comprised of subsystems: technological and pedagogical (Robertson, 2008). This further describes the shifting power relations between instructional designers and faculty (Robertson, 2008). Namely, institutional managers control financial and other resource allocation, including instructional designers (Robertson, 2008). So while faculty remain gatekeepers to the pedagogical (i.e., teaching and learning) system, instructional designers buffer conflict among these subsystems (Robertson, 2008).

Activity theory is uniquely positioned to explore sustainable change management, especially in e-Learning, by examining traditionally insulated assumptions, values, and beliefs comprising an activity system. Robertson (2008) notes: 
If we assume that the object of each activity system is an increase in e-learning the outcome of the object will vary between the systems. The organizational activity system - largely represented by management - has primary responsibility for the physical, financial and human resources of the organization. The desired outcome of the organizational activity system is organizational sustainability. The technological activity system - largely represented by information technology specialists - whose primary responsibility is for the health of the organizations information technology systems (both administrative and teaching) will desire technological sustainability. The pedagogic activity system -represented by those with primary responsibility for teaching and learning - will desire a rigorous and sustainable pedagogy. (p. 819)

\section{Summary of Methods}

The higher education social system includes local structures of belief, hierarchies, stratification, and recurring patterns (Hall, 2003; Morrill, 2008). Emergent and historically conditioned roles of work, professional identity, meaning, locally negotiated customs, interaction, and social meaning inform the perspectives of the higher education community (Coser, 2011; Engeström, 2001; McGinty, 2014; Shafritz, Ott \& Jang, 2011). The activity system, a university in this study, will be used to examine the working context and social connections of instructional designers (Barab et al., 2003; Szekeres, 2004, 2006). Probing, datarich questions of participants that address context, social environment, and sense of self are essential to understanding the activity system. Incorporating multiple data nodes within the bounded social system provides a robust view of professional identity in the corporate university.

More specifically, this study will describe personal experiences of instructional designers at the University of Missouri System, comprised of 4 research universities in the Midwestern 
United States. Congruent with national trends in decreasing state funding, the University of Missouri System has engaged in entrepreneurial activities to increase enrollments, including expanding e-Learning initiatives (MizzouOnline, 2014). Approaching this research as an instrumental case study, I have purposefully selected the setting of a land grant, flagship, public research institution engaged in revenue-generating e-Learning activities (i.e., 70 online program options, $\$ 8$ million in annual net revenue, $\$ 6$ million investment in new program development, national recognition for innovation in online education). This setting provides context in which to understand the experience of instructional designers working in a dynamic academic capitalism context.

The study will be conducted within the University of Missouri System, which is a unified, bounded system (Merriam, 2009; Stake, 1995). I will ask participants to elaborate on the lived experience of being a managerial professional in this bounded system through a "particularization" selection processes, instead of a more generalized or random approach (Stake, 1995, p. 8). This university setting incorporates a central educational technology support unit with several instructional designers, who merge both technology as well as pedagogical support, in addition to instructional designers embedded in various schools and colleges. The entire population of 17 practicing instructional designers across the university will be invited to participate in the study. Instructional designers practice in a multiple disciplines and diverse physical settings on the same campus, allowing me to "capture the realities, complexities, and subtleties of context-specific phenomena" (Mars \& Rhoades, 2012, p. 442). Because designers are housed within academic units or assigned to support specific units, relationships between faculty and instructional designer is unique and disciplinarily embedded (Rhoades, 2001, 2012). 
These varied disciplinary perspectives will provide a nuanced understanding of instructional designers' professional identity and relationships with faculty. Data will be collected through:

- initial in-person interviews with participants;

- participant self-reflective journaling/calendar annotations; and

- a final, post- journaling interview to discuss emergent themes.

First and foremost, my responsibility is to understand the participants' experiences and explore their worldview and thought processes (Stake, 1995) about working as an instructional designer at one of the University of Missouri System campuses. Throughout data collection, I will analyze data with the research questions in mind and those data will inform subsequent participant interviews and interactions. This process will assist me in organizing, describing, interpreting, and articulating meaning in the data (Wertz et al., 2011). In addition, interviews will be transcribed, read thoroughly, and subsequently coded line-by-line for each case participant (Tracy, 2010). I will also use axial coding during data analysis to identify thematic repetition, data categories, similarities and differences and analogies within and between data sources (Boeije, 2002; Ryan \& Bernard, 2003). I will employ an array of techniques to enhance trustworthiness, including triangulation, member checks, and creation of an audit trail to establish a more rigorous and credible study (Anfara, Brown, \& Mangoine, 2002; Coo \& Trent, 2006; Dressman, 2008; Johnson \& Onwuegbuzie, 2004; Ryan \& Bernard, 2003).

\section{Significance of the Study}

New structures and relationships bring with them new practices, identities, and values that shape culture. Institutional research tends to focus on established innovation but fails to examine the role actor constituencies play in creating and diffusing change (Lounsbury \& Crumley, 2007). With little knowledge of the role managerial professionals play in the diffusion 
of academic capitalism, I suggest an incomplete picture of the evolution of the corporate university has been presented. For instance, "less attention has been directed to social relations within organizations and within professions, between managers and professionals, or between different segments of a profession" (Rhoades, 1996, p. 628). Further, study of disruptive innovations in higher education have been too narrowly focused on the faculty perspective or more generically on institutional managers, and entrepreneurial change (e.g., Amaral, 2013; Bratianu \& Stanciu, 2010; Bratianu \& Stanciu, 2010; Ehrenberg, 2002; Johnstone \& Marcucci, 2007; Kirshstein \& Hurlburt, 2012; Rhoades, 2005; Rhoades \& Sporn, 2002; Slaughter \& Rhoades, 2004; Szekeres, 2006; Tuchman, 2009; Weerts \& Ronca, 2012; Werf \& Sabatier, 2009). This study will broaden the focus to include a growing group of managerial professionals in the corporate university, instructional designers, who have a particular role in the teaching (and learning) process at the university.

Higher education is tremendously complex; it is therefore essential to inquire, describe, and embrace various truths from a breadth of perspectives as they present themselves. Presenting the lived experiences of managerial professionals, this study attempts to enhance understanding among higher education stakeholders to minimize acrimony and misunderstanding, and ideally improve student learning outcome performance measures and learning engagement. Primarily, this study significantly contributes to understanding one aspect (i.e., teaching) of a changing culture in higher education.

Instructional designers operate within several domains, including interpersonal, professional, structural, contextual, and change (Fyle, Moseley, \& Haynes, 2012). They interact with administrators and faculty, formally and informally, and interpret actions through the dominant cultural lens and symbols (Garud, Hardy, \& Maguire, 2007; Rhoades, 2007; Simmel, 
as cited in Kivisto, 2011). For these reasons, they play an important role in the evolving and revenue generative instructional role of the university. Thus, this study seeks to move beyond a binary focus on faculty and administrators to appreciate the interconnected, nuanced, and interdisciplinary nature of higher education. Research into the instructional design profession will begin to explore fresh insights into the higher education social system.

\section{Definition of Terms}

Terms defined in this section comprise key concepts related to the current study. As noted throughout this chapter, themes and concepts related to higher education, activity theory, and disruptive innovation bring to bear critical ideas of higher education as marketplace in transition.

\section{Academic Capitalism}

Slaughter and Rhoades (2004) developed the theory of academic capitalism to describe the increasing engagement of higher education institutions in the competitive marketplace. Academic capitalism is a multidisciplinary, self-conscious social critique aimed at higher education commercialization and erosion of professorial independence (Horkheimer, as cited in Kivisto, 2011; Leonardo, 2004; Slaughter \& Rhoades, 2004). While this study does not purport to advance social critique about academic capitalism, it is used to situate the environment that bounds this study.

\section{Buffers}

Buffers facilitate a "serially interdependent occupational division of labor" (Barley, 1996, p. 420). Buffers need to develop formal, contextual, semiotic, and heuristic knowledge of local idiosyncrasies to both implement the administrator's agenda and partner with faculty, although they live in different social contexts (Barley, 1996). This study examines the role of 
instructional designers as buffers between faculty and administration within an institutional culture of change.

\section{Corporate University}

The term corporate university describes institutions where academic capitalism and entrepreneurial agendas are manifest (Tuchman, 2009). Corporate university will be used throughout the study as a singular term integrating both academic capitalism and entrepreneurialism.

\section{Disruptive Innovation}

Disruptive innovations occur in a marketplace, such as higher education (Christensen, 1997, 2006). In higher education, disruptive innovations include public demands for accountability, massification, a student-as-consumer mentality, and the implementation and instructional unbundling of e-Learning as a means to generate new revenues. These disruptions impact competition between institutions, access to new student populations, and changes to the structure and procedures in teaching.

\section{Instructional Designer}

Instructional designers operate as quality assurance-focused managerial professionals existing for the professional development of faculty, the production of teaching output, and directly contribute to the changing nature and culture of university life (Rhoades, 2007). Professional roles include, but are not limited to, online teaching development and support for faculty, course content review, guidance with instructional objective and learning outcome development, and technology training. Instructional designers provide a specific value proposition to instructional unbundling in this way: consulting on teaching interventions with 
faculty to overcome instructional barriers including encouragement, time, resources, student demographic analysis, and individual recognition and reward (Herman, 2012).

\section{Instructional Unbundling}

Instructional unbundling is the practice of dividing instruction into distinct tasks performed by experts in areas such as instructional design, curriculum delivery, assessment, and quality improvement (Smith, 2008). For the purposes of this study, instructional unbundling is advanced as a disruptive innovation to the production of curriculum and delivery of instruction.

\section{Managerial Professional}

Managerial professionals are those who facilitate entrepreneurial actions through the production of quality higher education. These professionals include those tasked with delivering services unbundled from the professoriate. Student services and residential life professionals result from certain student-specific aspects of the professoriate being unbundled. Instructional design professionals work one-on-one with faculty with unique access to, and influence on, curriculum development that once was the exclusive domain of faculty (Ebert-May et al., 2011; Rhoades \& Sporn, 2002).

\section{Massification}

Massification is rapid enrollment growth within a university, as a means to increase access, enrollments, and revenues (Alexander, 2000). Relevant to this study, massification costs may be mitigated by teaching technology to support e-Learning (Vedder, 2004). This strategy allows for increased student enrollments without the capital expenditure needed for facilities, as well as the cost-saving strategy of creating archivable and reusable teaching artifacts (e.g., recorded lectures). Moreover, massification and learning technologies may better engage 
students and maximize retention (Parish, 2013). Massification, although debated, is oft cited as scalable, affordable, and measurable in terms of cost, time, and learning (Parish, 2013).

\section{Summary}

Internal and external pressures on higher education to generate new revenue have necessitated market-based innovations such as corporatization, marketization, managerialism, and accountability (Austin, 2002; Brooks \& Miles, 2010; Doyle, 2010; Lewis \& Fisarelli, 2010; Robst, 2000; Sandeen, 2014; Steck, 2003; Szekeres, 2004; Wood, 2013). Instructional unbundling is one way universities are opting to support massification, which is central to many universities' academic capitalist behaviors. Within this context, I suggest examination of instructional designers unique positionality will provide a more complete picture of the implications of instructional unbundling and other disruptive innovations (Christensen, 1997, 2006; Coates \& Goedegeburre, 2012; Fumasoli \& Stensaker, 2013; Hardre \& Chen 2008;

Rhoades, 2001; Sandeen, 2014; Whitchurch, 2012; Williams van Rooij, 2011).

This chapter has described the various pressures on higher education to generate new revenue, integrate instructional unbundling, and implement new instructional modalities such as e-Learning. The scope of these disruptive innovations influences the division of labor at universities and has prompted the expansion of new professional roles, including instructional designers. Activity theory provides a framework to research the managerial professional and how they negotiate their work and relationships. This theory will guide the instrumental case study that follows in subsequent chapters. 


\section{CHAPTER 2: REVIEW OF LITERATURE}

Public higher education has evolved from substantially state-funded organizations to revenue-generating enterprises, focusing on minimizing costs and maximizing profits (Ehrenberg, 2006; Johnstone \& Marcucci, 2007; Kirshstein \& Hurlburt, 2012; Rhoads, Sayil Camacho, Toven-Lindsey, \& Berdan Lozano, 2015; Weerts \& Ronca, 2012). While debates around instructional unbundling persist, institutions continue to develop comprehensive strategies that include unbundling to attract students and the means to bolster academic success (Doyle, 2010; Ehrenberg, 2002; Johnstone \& Marcucci, 2007; Robst, 2000; Rhoads, Sayil Camacho, Toven-Lindsey, \& Berdan Lozano, 2015; Sandeen, 2014). Subsequently, higher education is now replete with market-based disruptive innovations, where education is a product to be packaged, marketed, and sold (Mars \& Ginter, 2012).

To practically implement many of the emerging entrepreneurial initiatives, contemporary higher education has embraced new and varied interdisciplinary teams of professionals (Fumasoli \& Stensaker, 2013; Hardre \& Chen 2008; Rhoades, 2001; Sandeen, 2014). Disruptive innovation and institutional change occur through the interaction of actors and practical activity (Jarzabkowski, 2003). Constituencies, such as faculty and instructional designers, may hold differing values and understandings of the social system in which they operate (Jarzabkowski, 2003). Given new patterns of practice and activity may arise, altering established patterns of interaction and activity, tensions between actors are likely to arise (Jarzabkowski, 2003). For the purpose of this study, I am interested in those who contribute to the instructional mission. These multi-professional teams of academic and professional staff have overlapping and interrelated outputs (Barley, 1996; Engeström, 2000, 2004; Whitchurch, 2012; Williams van Rooij, 2011). 
Activity theory will provide a lens through which I will examine "social interaction within particular historical and cultural contexts" (Jarzabkowski, 2003, p. 24). Specifically, activity theory incorporates an additional analytical dimension of practical activity and actor engagement over time provides a richer understanding of actor interaction than with social theory alone (Jarzabkowski, 2003). Activity theory effectively examines interactions among actors and practical, output-based activity, as well as the broader social structures (Blackler, 1993; Engeström, 1999, 2000, 2001; Jarzabkowski, 2003). This study will employ four interactive components of activity theory: organizational structures and actors; activities (actions); system conventions and norms; and processes governing interaction (Jarzabkowski, 2003). In the corporate university, these conventions include resource allocation, supervision and coordination, and goal setting (Jarzabkowski, 2003). This study defines the university as an activity system.

Below, I will review the literature relating to the cultures, values, and perspectives of key higher education stakeholders: university management, faculty, and instructional designers using activity theory as a guide. First, I examine the social system, customs, and community of higher education in which managerial professional operate. Next, I review literature about the associated mediating artifacts such as instructional design practice; division of labor among the community; and the object of entrepreneurial action through the production of quality higher education (Daniels, 2007; Engeström, 1999, 2000, 2001; Rhoades \& Sporn, 2002). Managerial professionals, the subjects of this study, are at the forefront of dealing with disruptive innovations and responsible for implementing an entrepreneurial agenda (Christensen, 1997, 2006; Dobson \& Conway, 2003; Engeström, 1999, 2000, 2001; Slaughter \& Rhoades, 2004). 
This chapter will close with an examination of their professional identity development that is historically, socially, and culturally situated (Daniels, 2007).

\section{Higher Education as an Academic Capitalist Enterprise}

In conjunction with a slowing economy, state revenues to public higher education have fallen $20-24 \%$ over the last 2 decades, taking a toll on direct institutional funding (Cheslock, 2006; Courant, McPherson, \& Resch, 2006; Ehrenberg, 2006; Kirshstein \& Hurlburt, 2012; Weerts \& Ronca, 2012). Colleges are "lucrative marketplaces" (Metcalfe, 2006, p. 462) and revenue generation has subsequently become a key concern among public higher education institutions (Leslie \& Rhoades, 1995; Rhoades, 2005; Tuchman, 2009). Higher education organizations must adjust to changes in their environment if they are to thrive (Shafritz, Ott, \& Jang, 2011). Resulting institutional transformation is due in no small part to public demands for higher education to prepare students for the workforce, cut costs, and improve quality (Rhoads, Sayil Camacho, Toven-Lindsey, \& Berdan Lozano, 2015; Tuchman, 2009). Universities as activity system are characterized by unique attributes such as loosely coupled structures and norms (Weick, 1976) and organized anarchies for activities, practice, and governance (Cohen \& March, 1974; Zott \& Amit, 2010). These characteristics contribute to a slightly less corporate, and more diverse, organizational structure designed to meet political, legal, and social obligations (Jarzabkowski, 2003; Robertson, 2008).

At the same time institutions are cutting costs, they have become increasingly reliant on generating new revenue primarily through increasing student enrollments (Rhoades, 2005;

Tuchman, 2009; Werf \& Sabatier, 2009). In lieu of substantial capital investment into facilities and other residential campus expenditures, institutions have turned attention to attracting students through enhanced access to increasingly more convenient and flexible course modalities 
(Allen \& Seaman, 2011; Pastore \& Carr-Chellman, 2009). One means of expanding market share, increasing revenues, and maximizing flexibility is increasing the number of online courses and programs (Rhoades, 2005; Rovai \& Downey, 2010). To advance this change agenda, institutions have increased instructional unbundling as a scalable and flexible means to focus scarce resources in massification (Neely \& Tucker, 2010).

These new ecologies of practice and performance necessitate a certain super-complexity of the academic capitalist workforce, diffusing academic control from faculty to managers and other support professionals (Williams, 2008). To address these disruptions, new forms of academic managers are needed to better leverage teaching and learning services of the modern university (Szekeres, 2004). Moreover, in this evolving landscape, faculty need the support of managerial professionals, such as instructional designers, to perform teaching duties in new, online modalities (Whitchurch, 2012).

Students are clearly engaged in the e-Learning marketplace. A Sloan Consortium survey (2013) found 7.1 million students, or roughly $33.5 \%$ of the total higher education student population, were taking at least one online course. Even at a primarily residential institution, such as the University of Missouri, e-Learning programs are reported to serve 3,227 nonresidential students (MizzouOnline, 2014). Moreover, in fiscal year 2013-2014, over $\$ 16$ million in net revenue from distance instruction was distributed to academic units. As has been argued earlier in this chapter, one means to attract and retain these nontraditional students is to create a division of labor called instructional unbundling.

\section{Instructional Unbundling}

e-Learning necessitates demands a change in pedagogy to avoid simple knowledge transmission performativite engagement (Carter, Sturm, Gonzales Geraldo, 2014). To extend 
academic programming, institutional administrators seek to redesign and modernize instructional development through instructional unbundling. Institutions must balance instructional production and delivery; quality; and ensure a sustaining, robust revenue stream (Allen \& Seaman, 2007; Brooks \& Miles, 2010; Guess, 2008; Pastore \& Carr-Chellman, 2009; Sandeen, 2014; Werf \& Sabatier, 2009; Wood, 2013). Leveraging limited faculty time has resulted in increasing personnel in the instructional division of labor, further unbundling faculty roles (Johnson, 2012; Plater, 2008). Academic work is a highly autonomous, differentiated profession and instructional unbundling is a further differentiation by redistributing control over academic resources (AAUP, 1996; Mendoza, Kuntz, \& Berger, 2012; Rhoades \& Slaughter, 1997).

Instructional unbundling developed as the practice of dividing instruction into distinct tasks performed by experts in areas such as instructional design, assessment, and quality improvement (Smith, 2008). Unbundling allows experts to contribute value to components of instructional output in a manner similar to an assembly line (Fyle, Moseley, \& Haynes, 2012; Rhoades, 2007). Faculty in unbundled settings are managed as professionals, not independent academic operators whose role is to deliver content. These increasingly common configurations have significant implications for those managerial professionals whose professional identity is formed and maintained in a culture of change and divisiveness (Campbell, Schwier, \& Kenny, 2007; Kezar \& Eckel, 2002). Viewing faculty as a managed labor force has long been a tradition at for-profit institutions, although these business practices are becoming increasingly translated and adopted at public institutions sparking alternate workforce arrangements (McLendon \& Eddings, 2002; Rhoades \& Slaughter, 2004). 
To best support faculty, managers have hired instructional designers to provide a specific value proposition to instruction; designers serve to teach faculty interventions for overcoming instructional barriers including encouragement, time, resources, student demographic analysis, and individual recognition and reward (Herman, 2012). Ultimately, instructional unbundling is a means to deliver thorough and comprehensive teaching and technology support to faculty.

\section{Faculty as Managed Professional}

Can professors do it all in the contemporary, corporate university? Faculty workloads are a significant obstacle to e-Learning adoption (Baiyun, 2009). In 2009, 34.4\% of faculty surveyed by APLU/Babson/Sloan Foundation developed or taught an online course (Herman, 2012). Faculty encounter different challenges in the online classroom due in no small part to unfamiliarity with the modality and technology (Herman, 2012). Faculty work is not necessarily an integrated whole, but rather distinct delineation exists between research, teaching, and service (AAUP, 2010). Nyquist et al. (1999) note the effective devaluing of teaching over research in general. Moreover, "exceptional teaching is of marginal worth" in the corporate university (Tuchman, 2009, p. 115). Subsequently, some scholars reject the anachronistic notion of an interdisciplinary expert in teaching, research, and service, but assert more contemporary notions of a highly specialized faculty (Coates \& Goedegeburre, 2012; Nyquist et al., 1999). In the eyes of administrators, instructional unbundling simply accepts the view that "the competences needed to excel in teaching do not necessarily coincide with those needed for research', (Enders \& De Weert, 2009, p. 878).

While the focus of this study is on managerial professionals, faculty culture, history, rules, and power are critical to understanding the context in which managerial professionals operate. Faculty constituencies hold a prominent position in the higher education community. 
Whereas classroom-based teaching has been historically characterized as the exclusive domain of a highly autonomous professoriate, several factors have substantively contributed to a shift to a more team-based systems approach to courses (Hardre \& Chen, 2008; Moore \& Kearsley, 2012; Rhoades, 2007; Rogers, 2003). e-Learning has shifted the locus of power from faculty to other professionals, disrupting longstanding authority and power of the professoriate.

When viewed as a workforce, faculty are considered a means to maximize prestige and generate external funding, oftentimes resulting in feelings of anguish and burden resulting from diminished autonomy (Demps, Lincoln, \& Cifuentes, 2011). Contributing to their sense of lost autonomy is instructional unbundling that shifts some of the control faculty have felt in the classroom to other professionals to assist in designing courses in an e-Learning and academic capitalism environment (Craig, Amernic, \& Tourish, 2014; Rhoades, 2007; Whitchurch, 2012). Faculty view these new managerial professionals as undermining their professional autonomy (Hardre \& Chen 2008; Green, 2003; Johnson, 2012).

However, it is commonly held that an e-Learning learning environment requires distinct engagement from instructors to navigate social and professional roles, multiple modes of instruction, and student ownership in learning (Almala, 2005; Garud, Hardy, \& Maguire, 2007). The challenge of aligning priorities and goals among faculty as managed professionals is essentially cultural: faculty do not perceive e-Learning as rigorous and meaningful, therefore resist its adoption; whereas institutional administrators see e-Learning as a means of keeping their institutions financially viable (Alexander, 2000; Austin, 2002; Brooks \& Miles, 2010; Doyle, 2010; Lewis \& Fisarelli, 2010; Robst, 2000; Sandeen, 2014; Steck, 2003; Szekeres, 2004; Wood, 2013). 
Does e-Learning improve instructional quality or simply automate teaching function and shift instructional delivery to a lower-level workforce (e.g., instructional designers, teaching assistants) (Rhoads, Sayil Camacho, Toven-Lindsey, \& Berdan Lozano, 2015)? It is important to draw a distinction between activity and practice (Lounsbury \& Crumley, 2007, p. 995). Activities presume activity leading to an output of some kind, whereas practice is a more normative, cultural convention governing behavior and activity (Lounsbury \& Crumley, 2007). Performativity assumes the individual performance of practice both reproduces and alters establishes a given practice, oftentimes through strategic planning (Lounsbury \& Crumley, 2007, p. 996). This assumes quality instruction was indeed a priority of faculty at research institutions.

Exploring the functional differentiation, beliefs, and power held by the academic profession is core to understanding their role in higher education (Rhoades, 1983). From the faculty perspective, they are the principal technology of production in universities (Leslie \& Rhoades, 1995). The discourse around academic capitalism has an adversarial tone and dismissive attitude framed by what faculty scholars refer to as vocational education and a public perception of "faculty as self-interested careerists" (Rhoades, 1996, p. 626). Although stratification in the professoriate is commonplace, reorganization of faculty ranks into a professional managed workforce has decreased tenured positions and maximized managerial flexibility in hiring (Rhoades, 1996; Rhoades, Kiyama, McCormick, \& Quiroz, 2008). A robust review of the evolution of higher education find seeking legitimacy, especially among faculty, was more important than efficiency (Kavanagh, 2009). Over time, and especially given the current shift to instructional centralization, manager-centered power is seen by faculty to be a "coercive and normative pressures that institutional agents impose on organizations" (Kavanagh, 2009, p. 576). 


\section{Faculty Attitudes about e-Learning}

Many faculty perceive an essential commodification of the college experience by fundamentally changing institutional culture, goals, assumptions, processes, and products (Rhoades, 1983, 2007). Institutional change of this nature will inevitably impact the professorate. The shifting conceptions of the traditional faculty roles in curriculum and fears that e-Learning has been embraced by universities due to an economic model rather than an educational motivation are two noted sentiments (Kriger \& Scheuerman, 2000; Marek, 2009). Faculty find relatively little value in the claim technology enhances student learning outcomes; rather they see it as compromising faculty autonomy and diminishing the promise of public good (Amaral, 2013; Johnson, 2012). Moreover, participating in e-Learning appears to be predicated on instructional unbundling, which may further serve as a barrier to participation (Amaral, 2013; Johnson, 2012).

Entrepreneurial managers focused on revenue generation advance a discrete focus on teaching, without equal focus given to the other remunerated roles of faculty, which only serves to further decouple and narrow faculty roles (Rhoades, 2012). Administrators and students may have more positive attitudes toward e-Learning, but lingering skepticism among faculty remains (Jaschik \& Lederman, 2014; Santilli \& Beck, 2005; Yick, Patrick, \& Costin, 2005; Whitchurch \& Gordon, 2010). Negative perceptions of faculty, particularly tenured faculty, arguably influence the diffusion of innovation and acceptance of e-Learning programs. Limited financial resources have led to underfunded tenure-track hiring, which furthers the sense among faculty that resource allocation has been diverted to hiring alternative professionals (e.g., managerial professionals, contingent faculty) for whom managers have more power and control (Rhoades, 1996; Rhoades et al., 2008). 


\section{Rise of the Managerial Professionals}

Modern, industrial societies are comprised of a multitude of interrelated professional responsibilities (Barley, 1996). Universities have become increasingly complex systems with multiple professions overlapping where "professors are not the only profession on campus" (Rhoades, 2007, p. 129). Contemporary organizations have less formal and rigid hierarchies where a more diverse set of professionals perform interrelated and reciprocal tasks contributing to teaching, student learning, and program administration. With more complex working arrangements, old approaches to staffing are insufficient (Engeström, 2000, 2004; Gurr, 2004). Admittedly, the old and new knowledge/learning regimes "coexist, intersect, and overlap" (Slaughter \& Rhoades, 2004, p. 29). Subsequently, institutional actors must constantly negotiate reoriented institutional missions, structures, academic culture, and reward systems (Hoffman, 2011; Morrill, 2008).

The implications of broader accountability, quality assurance, and the massification regime in higher education influence decisions, professional configurations, division of labor, sense of community, and delivery of service (Rhoades \& Slaughter, 2004; Rhoades \& Sporn, 2002). New workplace configurations and professionals have led to massive growth of institutional managers to coordinate an increasingly complex, interdisciplinary higher education system (Hoffman, 2011). These new roles have accompanied manager-centered power structures with certain "coercive and normative pressures that [managers] impose on [faculty]" (Kavanagh, 2009, p. 576). As previously discussed, instructional unbundling is one such imposition.

Managerial professionals have become essential to implement instructional unbundling (Ebert-May et al., 2011; Rhoades \& Sporn, 2002). Managerial professionals "are closely 
subordinated to managerial power and closely linked to its purposes... they engage in activities related to producing quality education... and increasingly central to academic capitalism" (Rhoades \& Sporn, 2002, p. 16). With instructional unbundling comes the increased need to negotiate and clarify boundaries and responsibilities, at least in effective organizational bureaucracies with highly specialized, structured, and authority-centered customs (Birnbaum, 1988). This inter-operational complexity of new managerial professionals who intersect and straddle professional, support, and academic roles highlight the less than binary relationship between teaching and research (Coates \& Goedegeburre, 2012; Heeyoung Han, Kuchinke, \& Boulay, 2009). For the managerial professional, this may include working under the direction of multiple supervisors (Williams van Rooij, 2011).

Managerial professionals, as a class, are becoming increasingly specialized and differentiated, providing interdisciplinary expertise in teaching and learning support (Rhoades \& Sporn, 2002; Whitchurch \& Gordon, 2010). Commonly, these professionals serve as academic advisors, student and residential life professionals, and instructional designers (Rhoades, 2007). However, faculty view managerial professionals as support professionals intersecting both professional (i.e., academic) and management (i.e., administration) staffing categories (Rhoades $\&$ Slaughter, 1997, 2004). Unlike for faculty, for the managerial professional, the academic/nonacademic binary is divisive, exclusionary, and othering (Bolden, Petrov, \& Gosling, 2008; Dobson \& Conway, 2003; Whitchurch, 2012). Thus, interpersonal relationships with faculty, especially predicated on instructional unbundling, can be challenging (Chow, 2013). Labels such as support staff communicate "terminology of non-academic staff makes [managerial professionals] appear residual" (Szekeres, 2004, p. 134). However, given the interdependence and permeability of tasks in instructional outputs, the anachronistic conception 
of "dichotomies such as blue-collar and white-collar, mental and manual, worker and manager, exempt and nonexempt" become increasingly irrelevant and at times, discursive (Barley, 1996, p. 406).

Technological change and commodification of instruction has necessitated pedagogically-focused managerial professionals on campuses to provide guidance and support to faculty (Rhoades, 2007). Teaching in an e-Learning modality requires additional skills and time investment that directly impacts faculty workload (Johnson, 2012; Neely \& Tucker, 2010; Plater, 2008; Rhoades \& Slaughter, 2004). These instructional designers tailor learning experiences to specified learner characteristics (e.g., nontraditional learners), as well as ensure policy compliance, quality, and resource allocation at the direction of the academic manager (Fyle, Moseley, \& Haynes, 2012). The next section will detail the work of instructional designers, their role in instructional unbundling, and positionality in the corporate university.

\section{Instructional Designers as Managerial Professionals}

"How do academic staff sustain professional identities" (Calvert et al., 2011, p. 25)? Identity development in academic organizations is situated within the extensive history of universities as well as the internal and external cultural rules (Daniels, 2007). Instructional designers have a commitment to quality, high standards, and collegiality (Calvert et al., 2011; Fyle, Moseley, \& Haynes, 2012). The production of quality higher education gives instructional designers unique access to, and influence on, curriculum development, once was the exclusive domain of faculty (Ebert-May et al., 2011; Rhoades \& Sporn, 2002). Instructional design professionals bring a "depth of knowledge and broader transdisciplinary knowledge and skills" (Whitchurch, 2012, p. 103). Instructional designers support academic activity using sophisticated and specialized skills, or mediating artifacts, serving as an invisible support 
infrastructure for faculty (Engeström, 1999; Patchen \& Smithenry, 2013). These "task-related competencies" are especially critical in translating faculty classroom teaching experience to an eLearning modality (Kaptelinin \& Nardi, 2006, p. 218).

Professionalism, identity, and agency of instructional designers are essential elements to understand teaching output, student learning, research, and service (Calvert et al., 2011). "Professionalism symbolizes expert knowledge, detachment, prestige, and an adherence to occupational norms" (Prasad, 1993, p. 1417). Central to the professional identity of instructional designers is the production of instructional output such as course curriculum materials and learner assessments (Rhoades, 2007). Particularly crucial is the complexity and serially interdependence of tasks performed by faculty and instructional designers (Barley, 1996). Whereas faculty had complete responsibility for the teaching enterprise, a new divisions of labor emerges from instructional unbundling. Metaphorically, one can imagine a production line where different professionals guide each stage of production. From planning, to resource development, to delivery, and evaluation, each distinct stage of the teaching process is guided by different professional experts. Addressing content development, content knowledge, and teaching prowess is a complex equation to balance. A lack of clarity among roles, albeit interdependent roles, emerges when one group is changing (i.e., faculty) while another group emerges (i.e., instructional designers) (Dobson \& Conway, 2003). For e-Learning, instructional designers must have knowledge and skill to deploy innovative teaching and learning opportunities by leveraging technology within this environment.

Comprehensive instructional design services are comprised of technological as well as teaching expertise. While teaching skills are far more important than technology skills, faculty must perceive relative advantage in learning new technologies, compatibility with their teaching 
approach and philosophy, trialability, as well as observability in the effectiveness of e-Learning (Tabata \& Johnsrud, 2008). The nature and format of instructional design services vary greatly and include one-on-one consultation with faculty, formal certification programs as prerequisite to teaching online, and seminar-style presentations facilitated by instructional designers as well as faculty experts who have already taught online. In evaluating the programming formats preferred by e-Learning faculty, a majority preferred individualized consultations with instructional designers (Fyle, Moseley, \& Haynes, 2012; Herman, 2012).

Building trust with, modeling effective design and delivery strategies for, and providing moral support and advocacy to faculty are several ways instructional designers play an "active role in the transformation of learning systems in higher education" (Campbell et al., 2007, p. 645). Interactions, formal and informal, between instructional designers with both managers and faculty provide context for status differentiation, cultural symbols, and role formation (Berente \& Yoo, 2012; Blau, as cited in Kivisto, 2011; Collins, 1971; Garud, Hardy, \& Maguire, 2007; Mendoza, 2008; Rhoades, 2007). I use the terms buffer and broker to describe this unique positionality (Weick, 1976).

\section{Buffers}

As previously noted, instructional designers work closely with faculty and administrators. They serve as buffers, negotiating divergent axiologies between a faculty culture rooted in collegiality and an administrative culture rooted in bureaucracy (Dobson \& Conway, 2003). Principally, "instructional design is a social, relational process created and shared through language, which is a form of action" (Campbell, Schwier, \& Kenny, 2007, p. 650). Instructional designers spend more time coordinating the logistics and workflow of course development, mitigate conflicts between faculty and managers, and actively bridge constituencies across 
administrative units (Christensen \& Osguthorpe, 2004; Cox \& Osguthorpe, 2003; Fyle et al., 2012; Kiyama, Lee, \& Rhoades, 2012; Sandeen, 2014). With functional overlap in professional roles and outputs comes the increased need to negotiate and clarify boundaries and responsibilities (Baruch, 2004; Patchen \& Smithenry, 2013; Weick, 1976).

Instructional designers often mitigate conflict within the academic community and bridge constituencies as a hybrid of managers and faculty, belonging in both and neither worlds as insiders and outsiders (Levin \& Shaker, 2011). Buffers facilitate a "serially interdependent occupational division of labor," negotiating boundaries and priorities of managers and faculty (Barley, 1996, p. 420). Buffers need to develop formal and contextual knowledge of local idiosyncrasies to both implement their manager's agenda and partner with faculty (Barley, 1996).

However, teaching someone to use the technology is not the same as teaching someone to teach. Teaching, as a collegial process, is a critical skill to be successful in an e-Learning course. Teaching in an e-Learning modality, and central to instructional unbundling, requires additional competencies and time investment impacting faculty workloads, the division of labor, and occupational structure within higher education (Rovai \& Downey, 2010; Tallent-Runnels et al., 2006; Wiesenberg \& Stacy, 2005; Yick et al., 2005). Here, instructional designers provide structures designed to improve teaching practice, minimize participation barriers, and reduce a sense of isolation among faculty (Kanuka et al., 2007).

Historically, traditional classroom-based faculty have developed courses in relative isolation. Subsequently, faculty are highly resistant to the perception e-Learning necessitates new rules and processes for course development and management. To engender positive partnerships with faculty and effectively serve as buffer, instructional designers must build consensus and shared expectations while remaining sensitive to the importance of social and 
interpersonal context (Chow, 2013; Engeström, 2000, 2004). Assuming instructional unbundling is about efficiency, instructional designers leverage scarce faculty time in the production of instruction (Hardre \& Chen 2008).

While faculty and instructional designers work toward a common purpose (i.e., quality instruction), tensions may exist as both constituencies balance the culture and administrative demands of job performance (Whitchurch \& Gordon, 2010; Worthen, 2002). Faculty and instructional designers work independent of and dependent on one another; this dependency may engender a sense of weakened professional status (Whitchurch \& Gordon, 2010). Their identities converge and in this convergence, the perception of transferred authority from the faculty to design and implement curriculum to nonfaculty is met with skepticism and hostility (Whitchurch \& Gordon, 2010).

\section{Brokers}

Instructional designers play a crucial role as change agents through interpersonal interactions (Campbell, Schwier, \& Kenny, 2007). This role informs professional identity, professional practice, and collegial engagement with the academic community. Instructional designers may feel "powerless to create meaningful change and the resistance of institutions to change" (Campbell et al., 2007, p. 650). However, “instructional designers as agents of social change...is subverting the traditional system" (Campbell et al., 2007, p. 658). In the role of broker, instructional designers develop strategies to coordinate activities and understanding between administrators, faculty, and the larger technical community (Christensen \& Osguthorpe, 2004; Cox \& Osguthorpe, 2003; Rhoades, 2007; Wenger, 1998). Oftentimes, brokers serve as "actors in the middle" (Metcalfe, 2006, p. 472) who may enable, or block, communication between members of the network. In the case of e-Learning, instructional designers may be the 
single point of contact for faculty while brokering services with advising, technology infrastructure, and other campus offices.

\section{Summary}

The social, fiscal, and cultural pressures on public higher education have necessitated innovative and disruptive innovations such as corporatization, marketization, managerialism, accountability, and return on investment requiring managers to develop new models, systems, and structures in universities (Alexander, 2000; Doyle, 2010; Robst, 2000; Sandeen, 2014; Szekeres, 2004; Wood, 2013). While public higher education has evolved from substantially state-funded institutions to enterprises focusing on minimizing costs and maximizing profits, academic capitalism questions assumptions of public good, faculty roles, and academic freedom (Ehrenberg, 2002, 2006; Johnstone \& Marcucci, 2007; Kirshstein \& Hurlburt, 2012; Weerts \&

Ronca, 2012). Interdisciplinary teams of faculty and managerial professionals contributing to instruction have become essential to realize market-based innovations where education is a product to be packaged, marketed, and sold (Fumasoli \& Stensaker, 2013; Hardre \& Chen 2008; Rhoades, 2001; Sandeen, 2014). This is particularly relevant in the case of e-Learning. Instructional designers work with faculty to develop curriculum (e.g., learning objectives, assessments) and effectively deliver an e-Learning course through prolonged guidance and training.

The following chapter will detail the qualitative methodology used to explore the professional experiences of instructional designers at one corporate university. Activity theory will be used to explore the ambiguous, complex, overlapping, and permeable professional activities of instructional designers spanning organization and cultural boundaries (Barab, Evans, \& Baek, 2003; Engeström, Engeström, \& Kärkkäinen, 1995; Patchen \& Smithenry, 2013). The 
research context, participant selection and recruitment, data collection, data analysis, trustworthiness, and researcher positionality will be described. 


\section{CHAPTER 3: METHODOLOGY}

Social theory provides a lens through which I view social phenomena and how social systems function (Anyon, 2009). My worldview coalesces around social construction of meaning through interaction with the human community, making a qualitative approach to this research study essential (Creswell, 2009). My approach to reality is an embrace of pragmatic interpretivism as a lens through which human meaning is studied in naturally occurring contexts (Brewer, 2000; Prasad, 1993; Ybema et al., 2010). Here, reality is permeable and meaning is derived through social interaction (Prasad, 1993; Snow, 2001). Rather than accepting a singular, overarching paradigm to understand meaning, I accept multiple and often conflicting interpretations of meaning to study the "contrary yet interwoven facets of complex phenomena" (Lewis \& Grimes, 1999, p. 672). By selecting a case study design, this study explored understanding of the multiple interpretations of being an instructional designer in a corporate university.

\section{Research Questions}

More specifically, in this study my intention described the lived experiences of a particular group of managerial professionals (i.e., instructional designers) in the corporate university. The principal objectives understand the ways in which instructional designers negotiate identity in an academic capitalism context and maintain interpersonal relationships with faculty. Through a qualitative descriptive case study, I posed the following research question (Creswell, 2009; Merriam, 2009; Stake, 1995; Yin, 2009): how do instructional designers describe their role within the university? Additionally, the following sub question provides insights into instructional designers' principal working relationship: how do instructional designers describe their relationship with faculty? 


\section{Methodology and Method}

Academic culture directs behavior, social conventions, traditions, expectations, and customs in the higher education workplace (Amaral, 2013; Bratianu \& Stanciu, 2010; Crotty, 1998; Rhoades, 1983; Szekeres, 2006). Higher education is tremendously complex and I feel it is essential to inquire, describe, and embrace various truths as they present themselves. Qualitative methodologies allowed me to develop richer understanding of participant experience, realities, complexities, and subtleties of context-specific phenomena as well as situate myself within the study (Mars \& Rhoades, 2012; Merriam, 2009; Stake, 1995). Within this particular study of managerial professionals, there are a complex "system of significant symbols" worthy of deeper understanding, which were best explored through a qualitative methodology (Crotty, 1998, p. 53).

My ontological approach to sense-making and data analysis is guided by pragmatic interpretivism, where reality is not a given, but rather meaning and framing are constructed through interaction and situational symbols (Crotty, 1998). Knowledge is constructed contextually, socially, and between people (Crotty, 1998). This perspective is especially useful in the study of distinct interactions and dynamics within the system of higher education. My approach is aptly described as a "flexible dialogue with subjects and contexts" with "mutual exchange [of information]" between participants and researcher (Bott, 2010, p. 159). Herein lies my embrace of qualitative methodology — to acquire in-depth, personal understanding of phenomena (Boeije, 2002; Ryan \& Bernard, 2003; Stake, 1995).

As Coffman (2011) noted, social reality is experienced by individuals where research questions and approaches can access those realities. Multiple realities exist and impact experience; I allow for a breadth of interpretations (Stake, 1995). I ask myself, how do I know, 
what do I know, and what does it mean to the participant and me? I do not find it intellectually untenable to allow for both subjective and objective dimensions to reality; truth can be out there and in here (Dressman, 2008). As suggested by Creswell (2009), I remain flexible to find "what works" (p. 10) and embrace an adaptable approach to draw from qualitative methods.

\section{Method}

Through reflection of their performance of everyday professional activities and interactions, I explored the professional identity and positionality of instructional designers using a case study method. Case studies provide heuristic knowledge illuminating readers' understanding of the phenomenon under examination (e.g., instructional designers and their role in disruptive innovation) (Merriam, 2009).

The setting for this study were the four campuses comprising the University of Missouri System. The University of Missouri-Kansas City and the University of Missouri-Saint Louis are located in the urban hubs on the West and East sides of the state, respectively. The University of Missouri, located in Columbia, is a large, land grant university. The fourth and final campus is Missouri University of Science and Technology, located in Rolla.

Being positioned in at a single organization provides value through a unified, bounded social system (Engeström, 2000; Stake, 1995). I approached this study as an instrumental case study (Stake, 1995). It is my hope selection of the University of Missouri, as a bounded system, gives deeper insights into the phenomena or experiences of instructional designers as managerial professionals. My primary responsibility was to understand the case and participants (i.e., the instructional designers/managerial professionals), to "appreciate the uniqueness and complexity of [the case] embeddedness and interaction with its contexts" (Stake, 1995, p. 16). 


\section{Participant Selection and Recruitment}

This case study illustrates the situational experiences of the instructional designers, each of whom work in a different discipline and different physical settings in the same organization. Participants were purposely selected based on a single job title, Instructional Designer, generated from a publicly open university staff employment database. The participant population pool consisted of 17 instructional designers, and all those who volunteered to participate were accepted. My goal was to recruit all potential participants. To recruit participants, I sent an email inviting them to be involved in the study (see Appendix A). The invitation e-mail included an electronic copy of the informed consent form (see Appendix B). Once potential participants agreed, I scheduled a time for the first interview. Each participant, or data node, elaborated on the lived experience being an instructional designer through "particularization" of a single institutional setting and common job title (Stake, 1995, p. 8).

Given the unique nature of the instructional design profession and low number of participants across the four campuses, neither names nor pseudonyms were used to protect participant confidentiality. I chose to simply refer to "participants." Also, the population of 17 designers from which this study pulls were not equally disbursed across the four campuses, making it even easier to identify participants, should the participant be identified by campus. This is also the reason why I chose a single case study design, rather than treating each campus within the system as a case. For example, the UMSL campus only had two instructional designers at the time of data collection. To speak with any specificity about programs or services specific to the UMSL campus would clearly reveal participant identity, which I believe would comprise their ability to form and maintain trusting relationships with faculty. 


\section{Data Collection}

I selected individual participant interviews and documents as my principal data sources. To thoughtfully explore the multifaceted influence of a disruptive innovation such as instructional unbundling on professional instructional designers in the university setting, data collection was conducted in three phases: an initial interview, participant journaling, and a follow-up interview to discuss the journaling experience. These data sources provided both researcher-led (i.e., interviews) and participant-generated (i.e., journals) data (Carroll, Booth, Leaviss, \& Rick, 2013). I maintained a journal and generated analytic memos (e.g., setting, participant demeanor) throughout data collection and analysis to enhance the descriptive quality of data (Erlandson et al., 1993; Wertz et al., 2011). Interview transcripts, field notes, memos, and journals were used to create an impressionistic understanding of the phenomena.

\section{Initial Interviews}

Interviews were semi-structured, guided by an open-ended interview protocol (see Appendix C) generated from my theoretical framework and research questions to "tease out relationships... probe issues... and understand phenomena" (Stake, 1995, p. 77). The purpose of the initial interview was to discover insights into the complexities of working as an instructional designer in the corporate university (Stake, 1995). Interviews were conducted in a private location outside participants' work environment in a neutral setting (e.g., conference room on campus), or by phone, to allow for maximum comfort and candor. Given participant consent, hour-long interviews were audio recorded.

Given the unique and complex interactions and experiences of participants, as well as my own epistemological predispositions, the participants were treated as collaborators to the extent possible. I relished the opportunity to foster a collaborative relationship with individuals I view 
as educated, talented professionals, and looked forward to negotiating roles with study participants (Bott, 2010; Colyar, 2009). Additionally, I developed a trusting relationship by engaging participants in the research process and collecting data through multiple methods.

Initial interviews lasted between 30-45 minutes. Two interviews were conducted face-toface in the participants' private campus offices. The remaining initial interviews were conducted by telephone. Second interviews were much briefer, between 15-30 minutes. All were conducted by telephone. The variation of interview lengths were dependent primarily upon: (a) the time in which participants had worked in the instructional design profession, and (b) the scope of duties within their particular position.

\section{Participant Journaling}

For the second phase of data collection, participant-generated journals allowed for realtime self-reflection on experiences and observations working in higher education as well as relationships with faculty. I asked them to keep a once-weekly journal over the course of a month (e.g., each Friday of a given month). Each individual journal entry was submitted electronically to the researcher, via Box. In order to maximize participants' exploration and reflection, I used activity theory to construct open-ended journaling prompts (see Appendix D for journaling prompts).

The calendar annotations, or journaling, that took place following the initial interview and submitted prior to the second interview gave tremendous insights into the day to day work of the instructional designer. These documents provided me and the participants with broader insights into the daily and weekly scope of work covering a variety of topics including work with faculty, solitary design work such as curriculum review, and interactions with other professionals 
both within and outside of the designers' home departments. Especially salient was the contrasting nature of solitary and collaborative work within any given day.

While participants were instructed to simply annotate a 4-week period of their calendar, there was significant variation in the data provided. While one participant provided a screen shot of their calendar with hand-written text annotations, 2 participants submitted 13 page documents detailing each day including interactions with faculty and peers, team meetings, and workshops and other training sessions.

\section{Final Interviews}

The third and final phase of data collection with participants involved a follow-up interview with each participant to discuss emergent themes from the initial interviews and journals. As with the initial participant interviews, a semi-structured protocol was used (see Appendix E). Emergent questions and progressive refocusing during the follow-up interview was informed by the initial interviews and journals. The final interview was scheduled after phases one and two were completed. With participant consent, interviews were audio recorded. Prior to the final interview, I shared the transcript of the initial interview to the participants for member checking and follow up discussion. Both sets of interviews were transcribed for ease of analysis.

\section{Field Notes and Analytic Memos}

During and after each interview, I generated field notes and analytic memos. These included observations of the physical setting when relevant, participant demeanor, reflexivity, and topics or themes emerging in the moment (Bogdan \& Biklen, 2007; Merriam, 2009). Following field notes, analytic memos provided a mechanism for me to reflect on my methods, analysis, and ethical dilemmas. Field notes and memos were written in an electronic format to 
eliminate the need for subsequent data entry. Following data collection, organization, and transcription, data was managed using NVivo.

\section{Data Analysis}

Data have "embeddedness within the social structures of language, discourse, meaning, and practice" (Wertz et al., 2011, p. 63). The goal is to organize data into increasingly abstract units of analysis (Creswell, 2009). I approach a priori data analysis as a "patient, reflective, willingness to see another view" (Stake, 1995, p. 12), providing me with an ideographic understanding of the complexity of the case (Ponterotto, 2005). My interpretive analysis focused on techniques to organize, describe, interpret, and articulate meaning in the data (Wertz et al., 2011). Data were analyzed concurrent to data collection to provide a mechanism to identity thematic repetition, data categories, and similarities and differences between data sets (Boeije, 2002; Ryan \& Bernard, 2003). I borrowed analytic techniques from grounded theory to make meaning from the data (Patchen \& Smithenry, 2013; Strauss \& Corbin, 1990).

Following an initial review of data (e.g., initial interview transcripts, participant journal entries), I used line-by-line open coding to identify emerging themes and data categories (Creswell, 2013, Merriam, 2009). Concurrent to data collection, open coding notes regularities, patterns, words, or phrases in the transcript text (Bogdan \& Biklen, 2007; Creswell, 2009). In addition to emergent codes, I generated codes from my conceptual framework, including formal categories of activity theory including subjects, objects, community, mediating artifacts, rules, division of labor, and outcomes (Engeström, 1999; Miles \& Huberman, 1994; Patchen \& Smithenry, 2013). At this early stage of analysis, categories and themes were as expansive as possible (Merriam, 2009). Additionally, my positionality as an insider guided the identification of indigenous themes, or themes evident to a member of a specific subculture (Carroll et al., 
2013; Ryan \& Bernard, 2003). For example, an indigenous theme salient to the study location included the policies relating to the particularities of e-Learning at the university. Using my insider knowledge, I was able to explore such themes in greater depth.

Themes should be relevant to the study, exhaustive, mutually exclusive, and conceptually consistent (Merriam, 2009). As each set of participant data were coded line-by-line throughout data collection, a constant comparative analysis between participant interviews and journaling consisting of simultaneous coding and analysis further reduced data and refined thematic categories (Boeije, 2002; Glaser \& Strauss, 1967; Hora, 2014; Strauss \& Corbin, 1990). Themes were guided by context and social structures, how participants defined the context, their perspective and values, participants' way of thinking about the world, strategies for maintaining and developing professional identity, and relationship maintenance (Boeije, 2002; Bogdan \& Biklen, 2007; Ryan \& Bernard, 2003).

Next, I used axial coding to produce more formal categories through "interpretation and reflection on meaning" than open coding alone provides (Merriam, 2009, p. 180). This technique included thematic repetition, data categories, as well as similarities and differences across data sets to formulate a typology, and clusters of related concepts (Boeije, 2002; Domas, White, \& Marsh, 2006; Hora, 2014; Ryan \& Bernard, 2003, Strauss \& Corbin, 1990). These data reduction techniques further refined themes, categories, and subsequently informed the final interview protocol (Boeije, 2002). Analysis of the second interview transcripts and participant journals followed the same process outlined above.

\section{Trustworthiness}

An essential criterion for successful scholarship is demonstrating a sense of trustworthiness to the reader. I approached trustworthiness by maximizing credibility as scholar, 
transferability to similar contexts, dependability of data collection, and confirmability of data analysis (Lincoln \& Guba, 1986; Merriam, 2009; Miles \& Huberman, 1994).

\section{Credibility and Transferability}

I employed an array of techniques to enhance trustworthiness including data triangulation to create a more rigorous and credible study (Anfara, Brown, \& Mangoine, 2002; Coo \& Trent, 2006; Dressman, 2008; Johnson \& Onwuegbuzie, 2004). My engagement with participants throughout the study allowed for a thick, robust analysis of data (Merriam, 2009). This rich description additionally provides opportunities for readers to transfer findings to their own contexts. Member checks of the transcripts and ongoing peer debriefing with fellow researchers and faculty mentor was vital to study credibility and consistency (Caulley, 2008; Coo \& Trent, 2006; Erlandson et al., 1993; Stake, 1995). Additionally, my own reflective journaling throughout the study was critical to my own reflexivity.

\section{Dependability and Confirmability}

Multiple data points (e.g., two interviews, participant journaling, field notes) enhanced exploration of the complexity, contradictions, and interdependencies of participant data (Lewis \& Grimes, 1999; Lincoln \& Guba, 1985). Moreover, data collection and analysis procedures have been reported and described in fine detail. To maintain dependability, this detail included researcher reflexivity and decision-making throughout the research process. Moreover, a readily available and searchable audit trail provides transparency and confirmability through data collection, coding, and triangulation mapping (Anfara, 2006; Ryan \& Bernard, 2003).

\section{Researcher Role and Positionality}

I am an instructional designer with over 20 years of experience in higher education. One of the more fascinating aspects to my profession is the intersection of profession, culture, and 
custom on daily working life. Instructional design is inherently pragmatic, finding teaching and learning solutions for a given circumstance. As a managerial professional conducting this study, my own experiences as an active-observer/insider-participant become central components of reflexivity and require critical self-reflection (Lewis \& Grimes, 1999). Moreover, ongoing intensive reflexive examination of my own approaches, beliefs, values, identities, and experiences were essential (Trahar, 2011). Further, my own experience in the corporate university informs how I understand this research project.

As a member of the same instructional design community as participants in this study, I am fortunate to have ready access to maintain engagement with participants and sufficient depth of exposure, while allowing me to richly describe the historical, cultural, and social context. I was familiar to all potential study participants, having worked for the centrally-coordinated educational technology organization until 2012, which I leveraged in developing a partnership based in trust and honesty. By recognizing my positionality from the start and maintaining a journal and field notes, I engendered credibility, trustworthiness, and rigor in the study and in the view of my readers (Coo \& Trent, 2006; Colyar, 2009; Tracy, 2010; Wertz et al., 2011). Consistent with my methodological perspective, I make no claims of researcher objectivity, accepting "the perspective of the researcher is not only an inevitable but a very useful aspect of inquiry and problem solving" (Dressman, 2008, p. 60).

\section{Limitations}

As I have noted, reflexivity, credibility, and transparency are key concepts central to my research (Bott, 2010; Colyar, 2009; Nolen \& Talbert, 2011). Through examining my own role in the study, a primary concern is to construct awareness of the participants' experience while honestly and transparently maintaining a self-reflective eye (Tracy, 2010). Neglecting 
reflexivity is problematic and I would consider it a personal failure to not completely communicate my place in the study, especially where participant interviews are concerned (Harklau \& Norwood, 2001). Having worked on campus for more than 20 years, thoughtfully negotiating dual relationships between myself and participants was essential (Bott, 2010). These relationships included professional acquaintances and friends. Throughout the study, an awareness of and sensitivity to these relationships maintained my reflexivity (Bott, 2010).

It could be argued by focusing specifically on the instructional designer and faculty relationship, a potential study design limitation is the omission of institutional administrators or faculty participants. Extensive scholarship is available on the entrepreneurial pressures on institutions to expand into the e-Learning marketplace, including subsequent impact on and perspectives of faculty and institutional managers (e.g., Amaral, 2013; Bratianu \& Stanciu, 2010; Ehrenberg, 2002; Johnstone \& Marcucci, 2007; Kirshstein \& Hurlburt, 2012; Rhoades, 2005; Slaughter \& Rhoades, 2004; Szekeres, 2006; Tuchman, 2009; Weerts \& Ronca, 2012; Werf \& Sabatier, 2009). The dearth of research on the managerial professional perspective provided justification to explore these professionals' unique identities. However, my interest in contextspecific relationships provided only an instrumental account of the instructional design professional at the corporate university.

This study is heavily dependent on individual recollection, honesty, and self-selection (Hora, 2014). By implementing a multi-stage and multi-method research design, I triangulated data to minimize any related limitations. The selection of a single institution provides a descriptive, instrumental account of instructional designers as managerial professional. However, readers may not find the study or findings transferable to their unique institutional setting. Subsequent research set in various institutional settings including location, history, and 
institution type provides an even richer understanding but is outside the scope of this study. Further, participant recollections and candor in both the interviews and journals may pose a limitation (Creswell, 2009).

One final limitation regards activity theory's highly theoretical conceptualization of change and innovation through actor interaction and practice (Jarzabkowski, 2003). Activity theory does not purport to provide a holistic approach to capture how organizational change strategies are created or maintained (Jarzabkowski, 2003). In this study, I have not used activity theory to explain the origins of system contradictions or how conflicting values are sustained. Rather, activity theory provided an analytic lens to understand complex, overlapping, and interconnected roles, relationships, and hierarchies; processes; values and beliefs; and cultures (Haedicke, 2012; Patchen \& Smithenry, 2013).

\section{Summary}

Higher education is tremendously complex and it is essential to inquire, describe, and embrace various truths as they present themselves. Through analysis of interviews and journals of instructional designers, this case study examined the "temporal and spatial, historical, political, economic, cultural, social, and personal" experience of instructional designers in the corporate university (Stake, 1995, p. 43). Open coding individual participant data throughout data collection allowed for a progressive refocusing of codes. Subsequent axial coding drew thematic similarities and differences between participants and data sets. Strategies to enhance trustworthiness, including reflexivity and an audit trail, increased the likelihood of a credible study. 


\section{CHAPTER 4: FINDINGS}

This chapter explores the experience of instructional designers to understand changing professional roles of faculty and staff in contemporary higher education. This qualitative descriptive case study will explore the institutional context in which the participants operate as well as emergent themes found in the data. The principal themes were: participants' paths to the instructional design field; forming and maintaining interpersonal relationships or partnerships with faculty; barriers to forming these partnerships; and scope of services provided. Each theme influences the formation and maintenance of professional identity.

\section{Institutional Context}

To fully understand the collective bounded system of UM, it is necessary to provide some context related to work settings of the participants at the time of the study, which differ based upon the particular campus within the university system. I begin by outlining the unique characteristics of each campus including enrollments, student demographics, and numbers of faculty and staff for each campus. Next, I will provide an overview of each campus's respective instructional design units. Some detailed material was not available via each university's website so each overview will include varying levels of detail regarding enrollments and demographics as well as information regarding the units responsible for instructional design.

As noted in Chapter 3, the University of Missouri System is comprised of four campuses. As part of a system, each campus shares a series of resources including Canvas as a learning management system, registration, human resources, and student information systems. The university system has also placed an emphasis on online/distance learning as a means to increase higher education access to students and increase the number of net new students at the campuses (LaHucik, 2018). Subsequent to the initiation of this study, additional 
consolidation/centralization of resources has occurred. For example, MizzouOnline, which had been a division within MU Provost's office and was responsible for managing online courses and programs, is now part of the Office of eLearning at the University of Missouri System. As I provide details about the four system campuses below, I relied upon the data easily accessible on each university's website. Not all campuses provided the same level of data transparency. Thus, the campus descriptions vary in detail.

The largest campus is the University of Missouri (MU or Mizzou), located in Columbia, MO. The university's:

distinct mission, as Missouri's only state-supported member of the Association of American Universities, is to provide all Missourians the benefits of a world-class research university. We are stewards and builders of a priceless state resource, a unique physical infrastructure and scholarly environment in which our tightly interlocked missions of teaching, research, service and economic development work together on behalf of all citizens. Students work side by side with some of the world's best faculty to advance the arts and humanities, the sciences and the professions. Scholarship and teaching are daily driven by a commitment to public service — the obligation to produce and disseminate knowledge that will improve the quality of life in the state, the nation and the world. (University of Missouri, 2018, para. 1)

At the time of data collection, Columbia, MO was a city of 116,906 residents located in the center of the state (University of Missouri, 2018, para. 2). The university enrolled 30,870 students in the fall semester of 2017 including 23,817 undergraduates, 5,872 graduate students, and 4,978 minority students (University of Missouri, 2018, para. 11). The university had a total of 2,129 full-time faculty and instructors and a total of $\$ 248.3$ million in research-related 
expenditures in the 2016 fiscal year (University of Missouri, 2018 para. 14). Over the 20162017 academic year, the university offered 101 online degree options and nearly 1,100 online courses to 3,643 online students (University of Missouri, 2018, para. 16).

The MU central instructional design unit is Educational Technologies at Missouri (ET@MO). ET@MO was formed in 1999 to combine LMS management; instructional design; and faculty technology training into a single, faculty-focused center under the direct supervision of the Vice Provost for Undergraduate Studies. I worked at ET@MO from 1999-2014.

ET@MO's staff of over 30 includes instructional designers, developers, and editors as well as learning technologists (Educational Technologies at Missouri, 2018). Their scope of services includes Canvas (the LMS used by the university system) course creation, instructional design, and audio/video creation assistance including a media studio (Educational Technologies at Missouri, 2018). These services are available to faculty teaching in a traditional classroom as well as those who teach fully online. In 2010,ET@MO worked with individual colleges and schools to imbed instructional designers for more local faculty support. This model will be explored more closely in participant testimonials.

The second campus included in this study is the University of Missouri-Kansas City and as noted earlier, institutional information provided on the university's website varied significantly from that available on MU's website.

The University of Missouri-Kansas City's (UMKC) mission is to lead in life and health sciences; to deepen and expand strength in the visual and performing arts; to develop a professional workforce and collaborate in urban issues and education; and to create a vibrant learning and campus life experience. (University of Missouri-Kansas City, 2018, para. 3) 
Located in a major metropolitan area in the western part of the state, UMKC enrolled 6,699 students in the 2015-2016 academic year. In 2018, 825 of whom are designated as online students, and includes over 8,000 undergraduate and more than 5,500 graduate students (University of Missouri-Kansas City, 2018, para. 1). There were 1,172 full- and part-time faculty (University of Missouri-Kansas City, 2018, para. 1).

The University of Missouri-St. Louis's (UMSL) mission is "we transform lives" (University of Missouri-St. Louis, 2018, para. 3). Located in a major metropolitan area in the eastern part of the state, UMSL enrolled 16,715 students in the fall semester of 2017; of whom $82.4 \%$ were undergraduates and 59\% were women (University of Missouri-St. Louis, 2018, para. 4). The UMSL website did not provide any information on their instructional design group.

The Missouri University of Science in Technology (Missouri S\&T) is located in the southeastern part of the state with a mission to "integrate education, research, and application to create and convey knowledge that serves our state and helps solve the world's greatest challenges" (Missouri University of Science in Technology, 2018, para. 6). Their services include instructional design support as well as The Center for Advancing Faculty Excellence (CAFÉ). Their staff includes one instructional designer, technologist, and three instructional developers. Like UMSL, the Missouri S\&T website did not provide any student demographic information or information about their instructional design group.

\section{Paths to Instructional Design}

Participants presented a breadth of backgrounds and paths to the instructional design field. I note some basic demographic information in this section to provide context for the participants' backgrounds and years in the field. I believe this information adds a deeper understanding of participants preparation and professionalism. 
According to participants, the instructional design field has undergone significant growth since universities began to explore online courses and programs. "Our work is being noticed and it's exploding" one noted and another added "this past year, we actually hired another instructional designer and an instructional developer." Participants arrived in their role as instructional designer through a combination of formal education and professional experience, as illustrated below in Table 1. The primary paths of K-12 teaching, higher education employment, and instructional technology will be detailed further in this section. In addition, every participant expressed some degree of on-the-job training related to developing a professional competence.

Table 1. Participant Professional Backgrounds

\begin{tabular}{|c|c|}
\hline \multirow[t]{2}{*}{ Academic Background } & Master's Degree $=4$ participants \\
\hline & $\mathrm{PhD}=3$ participants \\
\hline \multirow[t]{2}{*}{ Academic Discipline } & Instructional Design $=2$ participants \\
\hline & Other discipline $=5$ participants \\
\hline \multirow[t]{3}{*}{ Years in the Instructional Design Field } & 1 to 5 years $=3$ participants \\
\hline & 5 to 10 years $=2$ participants \\
\hline & 10 to 30 years $=2$ participants \\
\hline
\end{tabular}

\section{Instructional Technology}

Some participants found their way to instructional design through a passion for working with technology. For example, one participant shared: "One of the things that I really enjoyed doing was incorporating technology into what I was doing. I really enjoyed putting courses together, seeing what new ways I could engage students in learning and doing that with technology." 
It was common for participants to use the technology as a lever to work with instructors in instructional design. On one campus, it was typical to work one's way through in a technologist role that led to instructional design, as one participant recounts:

I started as an instructional technologist first and I've actually only been a designer for, going on, it's like a year and a half, almost 2 years, I think. Typically, that's the progression here, is they look for someone who can start in the technologists role, to really feel out if it's someone who's more interested in the technology or more interested in the design. To figure out which path they would take.

Whereas in the subsequent two sections a focus on teaching and learning was central, these instructional designers came to the profession with a focus on technology. I will explore further in subsequent sections how this variation in roles and unit-specific foci creates a challenge in forming a consistent professional identity across participants.

Additionally, this variation in how participants came to instructional design has very real implications in the hiring process. One participant, who plays an active role in staffing their department commented:

I would say their preparation, it's across the board, because, as you know, since there are so many different types of instructional designers, [employers are] looking for something a little bit different. For me, I look for what I call a Swiss army knife who has just a lot of different skills.

This quote further illustrates a challenge in forming a professional identity. If expectations vary significantly among hiring committees, as well as variation in professional responsibilities, it makes it difficult for an instructional designer to develop a consistent, generalizable sense of professional identity. Other challenges will be explored in subsequent sections. 


\section{K-12 Education}

Several participants followed a path from K-12 education to work as an instructional designer in higher education. It was there that they developed a passion for teaching. Teaching at the elementary or secondary levels fostered participant appreciation for curriculum design, teaching methods, and to a lesser extent technology. Those participants who started their careers within a K-12 context shifted their focus to higher education after completed a master's degree. However, a passion and interest in effective teaching, which started in their K-12 experience, was able to flourish as an instructional designer in a university setting.

Well, I've been in the field of education for over 30 years. The first half, I taught elementary grades. The second half, I provided professional development in educational technologies for K-12 teachers. I think in the beginning [my role] was more about the technology than it should of been, and now [my role] seems to be including more of the pedagogy and the actual things that we say we want our instructors to do we're actually doing.

This quote highlights a certain trajectory many participants took from working in public K-12 schools, and an observation that initially, instructional design and similar support roles focused heavily on the technology itself rather than teaching and curriculum support. Some participant experiences, described later in this chapter, reflect a certain give and take when it comes to supporting the technology as a tool versus a focus on curriculum, interaction, and teaching expertise that instructional designers also offer.

\section{Higher Education}

Although some participants found instructional design through K-12 education, most participants began their careers in higher education. However, they tended to begin their higher 
education experiences in another area such as an educator in student services, librarian, or faculty member from another academic discipline. In these cases, again, a passion for teaching and student learning was a central part of their identity. Particularly for those in a teaching role, teaching with technology, either online or in a hybrid format, became a central focus of their work.

Coming from higher education, these designers were more adept at navigating the cultural norms that exist around faculty support. Especially for those who came from a teaching role and transitioned to the role of instructional designer, building relationships on the basis of a common history of teaching became a hallmark of expressing a professional identity. They viewed their working relationship with faculty as a collaboration or partnership as opposed to a support role. This competence in working with faculty figures into the hiring process:

It was hard to find somebody who had a deep technology toolbox and a lot of experience working in higher ed and who was a people person to really understand the nuances of what a faculty member sharing, to understand really what they mean and what's important to them. We would lean towards if they had experience with faculty almost as more important than some of the technologies, because the technologies change, and as long as someone's somewhat proficient in orienting themselves in a software program. This quote highlights the importance of understanding and navigating the cultural norms of higher education and more importantly, the professoriate. This skillset figures heavily into the development and maintenance of an instructional designer's professional identity. As the principle working relationship, interacting and consulting with faculty frames many of the facets of professional identity explored in this study. 
These participants, regardless of academic training or credentialling, reported having a more robust understanding of their role and professional identity. As discussed, this may be attributed to familiarity with higher education cultural norms, However, it is noteworthy that one participant reported that faculty thought of him as "the tech guy," although his new role was one focused on curriculum development and teaching.

\section{Creating Partnerships with Faculty}

The most consistent element participants reported of being an instructional designer was the necessity of forming and maintaining constructive, trusting relationships with faculty. These relationships form the basis for allowing faculty to explore their creativity in teaching and for the instructional designer to bring their own expertise in maximizing student learning. In addition, these partnerships allow instructional designers to provide alternative teaching strategies, because, oftentimes, instructional designers have worked with faculty from the same or different disciplines and are able to share approaches that have yielded benefits to both faculty and students.

The [instructor] who I have now, he's like, "Hey, this is what I'm thinking," and I get goose bumps. I go, “Oh my God. This is so awesome.” It's pretty fun when you can get not just the right person, but then you get the right team together and they can play off each other. They become really ... Okay, I'll be cheesy a little bit, it could be really magical.

This quote describes one way in which a positive working relationship, which I describe as a partnership, forms between instructional designer and instructor. Such a partnership emerges when an instructor develops an idea for some teaching intervention, consults with their instructional designer, and the two of them develop the requisite strategies and relevant 
technology solutions. This type of relationship is built upon mutual respect where each person is able to contribute their expertise.

The term partnership came up again and again in the initial interviews. "As you're building relationships, people are always going to come back to you to help solve problems." This participant's position evolved by building relationships, demonstrating competence, cultivating trust, and interfacing directly with all academic units on campus. Through this collaborative process, participants saw that faculty can reflect on their teaching and design. In addition, participants reflected that faculty valued the relationship because they report to their designers that through this process, they get to know students better online than face-to-face by focusing on 3-facets of interaction: faculty-student, student-student, and student-content.

A willingness to nurture these relationships was a common theme in the annotated calendars as well as in the second interviews. Flexibility and willingness to adapt and adjust to faculty needs promotes a more robust partnership. Being flexible and responsive to a host of demands including unscheduled office visits to diagnose a technical issue, curriculum reviews, hosting in-person and virtual workshops, and general project management have to be balanced.

\section{Developing an Interpersonal Bond with Seasoned Faculty}

All participants stressed the need to develop a close bond when working with faculty. Ways to develop this bond varied among the participants, depending on the scope of their role, but offering advice with care and sensitivity and a certain sense of vulnerability were common approaches. For example, one participant said, "Listen, and observe and take the time to learn [about their course] as much as possible. Learn about who they are as instructors to connect with them." Creating this bond involves a certain degree of vulnerability when offering advice on the design of a course. This vulnerability is reciprocated by faculty who are opening themselves up 
to feedback on their teaching, which can be an entirely new experience. This reciprocity often begins with the instructional designer. The quote below offers some insight from one designer who approaches vulnerability with faculty as leading by example:

Being able to be vulnerable yourself before you step into the realm of knowing that what you're going to say may potentially have the other person feeling a little vulnerable, is also really key that a lot of people forget to do is make yourself vulnerable first. Then people listen to you.

A second participant noted the importance of learning how to give advice and guidance with a sensitivity to faculty cultural norms:

I really had to learn quickly how to listen first and then provide recommendations second and not go in with, "Here's my ideas. Here's how I think you should change" and I think that translates exceptionally well to instructional design or anything where you kind of have to be a team. I'm working with nursing, for example, and they're building a whole program, and so I attend all of their meetings. I attend their faculty meetings. I don't even know that they realize I'm not a nurse. That sense of belonging is important to me personally, but I also think that it's because of the work that I do and the partnerships that we've created. It really is a partnership in learning that is central to my philosophy of instructional design, because I can't think of it as a service. I can't think of it as a help desk where people drop stuff off and I create magic.

These bonds can extend into other areas of collaboration with faculty. One participant described being invited to present at a conference by two faculty collaborators:

[The conference] wasn't actually in my field. I was presenting with two writing faculty that teach the writing and research class. They had done a redesign with me, and they had 
done a lot of collaboration with not only ed tech, but with the library and student success center. They wanted to do the presentation with all of us involved. I kind of just did the ID portion of their course.

Not only did this reinforce and celebrate the partnership that had been formed, but it provided a certain recognition of the value and talent the instructional designer brought to this particular course redesign project.

Geographic proximity to the faculty also influenced the kinds of professional relationships that developed between instructional designers and instructors. "Proximity and location can be a challenge but also can be a benefit to make house calls. Faculty prefer to meet in their own offices, where they work, but some others prefer [our] office to get out of the office." Generally, instructional designers managed this by offering to meet faculty in their office, the designer's office, or a faculty-focused educational technology lab/studio space when scheduling appointments.

One specific configuration implemented on the MU campus imbeds instructional designers within an academic unit instead of working in a centrally located department. This organizational structure led one participant to share:

Sometimes here out in the departments, we kind of feel like we're rogue field agents, sometimes. We have to find, you know, we have to get someone to trust us. We have to get someone to come to us with their project. So sometimes, what we often end up doing is helping them with their technology piece that leads us in to being able to help them with their design and other things.

This observation highlights two prevailing themes identified in this study. Firstly, instructional designers have a breadth of knowledge ranging from simple technology use to curriculum 
development and teaching practice. Secondly, being able address faculty needs, be it how to use PowerPoint or align their course outcomes with assessments, serves a higher goal of forming a trusting and productive partnership. It is worth noting, that although close proximity to faculty allows for more robust partnerships with faculty, participants who served in this imbedded role felt isolated from the broader instructional design community on campus. This sense of community as it relates to professional identity will be explored further later in this section.

In addition to working with seasoned faculty, who may lack of familiarity with the instructional design profession, which is detailed later as a barrier to developing partnerships, there are two other distinct populations of faculty participants singled out: new faculty and nontenure-track faculty. Creating partnerships with these categories of faculty look very different. The underlying priority with each remains the same, i.e., developing a productive, trusting partnership. However, the characteristics of each group in terms of familiarity with instructional design and willingness to work with an instructional designer vary significantly, requiring different strategies, approaches, and creativity.

\section{Partnering with New Faculty}

Either as a PhD student or in a previous faculty position, faculty new to the institution tended to be more open to collaborating with instructional design professionals. This can be attributed to previous learning management system experience or even the possibility they have previous online teaching experience. It may also be related to a generational shift in acceptance of digital technologies. The participant below captured these sentiments:

I think the nice part of really being pushed to new faculty, sometimes new faculty coming in often times are younger, so they're a little bit more open to those types of experiences, 
more open to that help. Also, too, they've potentially been in graduate programs where they've worked with an Instructional Designer, or they've heard that term.

Multiple participants made special mention of working with new faculty, particularly those who had previous professional experience working with an instructional design professional during their graduate studies. For the designers, this was markedly different than the experiences of working with more seasoned faculty, less familiar with instructional designers, outlined in previous sections.

Now some of them, and it's been great over the last year probably more so. They're coming in, "My other college had instructional designers. I had someone else that I worked with before." More and more these new faculty[who] are coming in understand [the] kind of an experience with someone who was coined an Instructional Designer. The term was out there.

As described above, familiarity with the instructional design profession establishes a certain sense of initial comfort. Because of the increased comfort and ease in forging relationships with new faculty, it contrasted from designers' experiences with more seasoned faculty, either tenured or teaching, who comprise the majority of participant partnerships.

\section{Partnering with Non-tenure Track (NTT) Faculty}

With this section, I make special note of the unique dynamics at play working with nontenure track faculty, especially parttime faculty. Participants described working with NTT faculty as different than working with their tenure track colleagues. Overall, the proportion of fulltime teaching or parttime adjunct faculty in the online space is higher than that of the tenure track according to multiple participant interviews. "We truly are here to help them. Once they start working with us, I would say nine times out of ten, some of the faculty are just, 'I can't 
believe I didn't do this sooner." For those NTTs who are parttime or adjunct, participants noted a common phenomenon of adjunct as outsider and appreciated how grateful those faculty felt for the support offered by the instructional designer:

I don't think a lot of instructional designers do as much with the adjuncts within the department as I do, and I think it's just because I can appreciate how much value those adjuncts add to the academic units. If it wasn't for these adjuncts, we wouldn't be offering all of these courses. Our fulltime faculty could not teach all of these courses. So, I've even had adjuncts tell me, "Wow, you're the first person to really help me." I even had one say, "Well, I think it's because I'm an adjunct. They don't see any value in me, but I can see value."

Working with parttime faculty was unique because these faculty rarely, if ever, have a presence on campus. These faculty feature heavily in the e-Learning space, often as practitioners, who do not have the same connection to the campus because the work remotely. Thus, institutional services, such as instructional design support, are less obvious and accessible. However, when they did find instructional designers, they found their support invaluable.

\section{Barriers to Collaboration}

Despite differences in forging relationships with each of the aforementioned faculty categories (i.e., seasoned, new, or NTT), certain barriers remain to forming partnerships and collaborations. Barriers to collaboration create obstacles for instructional designers to be as effective in their roles with faculty. The most salient factors that contribute to barriers are: the time necessary to cultivate relationships, initial misconceptions or familiarity with instructional design, and underlying skepticism of the professionalism of the instructional design profession.

\section{Time}


Participants universally noted that time to collaborate was a challenge. "I've talked to a lot of faculty, well, 'I'd really like to do this. I'd really like to do that, but unless I can get buyout time to make it happen, I don't think I'm going to do it."” Another participant noted, the biggest problem I have with a lot of faculty is getting them to actually sit down and invest the time and then following through with it sometimes, too. We may sit down and have a really good conversation, or even a couple of really great conversations, but if I don't get them going it kind of fizzles out, sometimes.

The relative size of the instructional design team further complicates the pressures on time, which this designer illustrated well: "we are seen on campus as small and mighty." Annotated calendars highlighted this point by showing the amount of time instructional designers spend in faculty offices while balancing responsibilities they have in their own workspaces. This speaks to the scarcity of instructional design as a resource to faculty. While on some campuses, those instructors developing and teaching fully online courses are given priority status, other campus configurations promote their services to all faculty in whatever teaching modality they may be engaged. Thus, the size of the instructional design workforce or the wider-ranging expectations can both contribute to the amount of time these professionals have to create the trusting relationships needed to be as successful as possible.

\section{Lack of Knowledge}

Participants reported that faculty members' lack of prior knowledge with or misconceptions about what value instructional design offers was another common barrier. Who are they? and What do they do? were questions that had largely gone unanswered for faculty, leaving it up to the designers to explain their value; this poses a unique hurdle early in the design process. Such skepticism and lack of knowledge about instructional design and the designers 
themselves made it difficult to establish trust, which is critical to forming and maintaining a successful partnership. One participant shared:

Faculty here get very concerned that we, as instructional designers, are trying to take their class and take ownership of their class or something like that, which is just not true. It is part of dispelling those myths or ideas that are incorrect in their mind about what we do. This quote goes directly to the matter of initial trust between designer and instructor. Without an understanding of designers' roles, faculty are immediately put off by what they perceive to be their roles. Possibly reflecting such misperceptions, other participants reported hearing statements such as "I don't know why we need you, necessarily."

Given this barrier, participants described that they had to commit to countering misconceptions. This is a process that unfolds over time that relied on building that interpersonal bond with faculty that was noted earlier in this chapter.

It's really interesting that some of the faculty that come in with this attitude of, "You're taking away my academic freedom," once they start working with us and they realize that ...[what] we're looking for [is] in terms of quality matters and online course and whatnot, they realized it's not really that bad. And it's almost like once you clarify those misperceptions and you get that information out there, they understand.

As this quote illustrates, it is a sustained effort to develop trust. And as was noted earlier regarding vulnerability, leading by example by demonstrating competence and trustworthiness can help overcome this hurdle, but it does take time to do this and with limited resources, it can push up against other barriers.

\section{Concerns Over Academic Freedom}

In the last section, a participant pointed to perceptions about their roles and assumptions about eroding a faculty member's academic freedom. Academic freedom concerns persist, as 
noted by one participant "the academic freedom. Oh, my gosh. I think we hear that probably once a week where some faculty member is thinking that we are infringing upon their academic freedom." It is a delicate balance to strike: recognizing teaching online is a new modality to which a pedagogical approach must adapt, while respecting content area expertise, previous teaching experience, and preferred teaching approaches. Of the designers who specifically mentioned faculty concerns over academic freedom, each approached the topic with faculty by referring to the policies governing their academic freedom and ownership of intellectual property, as well as reiterating that the designer's role is to simply offer advice and guidance but ultimately, all decisions about course delivery belong to the faculty member. When a relationship begins with a faculty member who is concerned that their fundamental right of academic freedom may be compromised, it is more difficult to establish the trusting, productive relationship needed for the design process.

\section{Narrow Definition of Expert}

In addition to the skepticism noted above, designers expressed that faculty appeared skeptical about their academic credentials, which further compounds a lack of initial trust and another obstacle to collaboration. Describing that skepticism, this participant shared:

I think some of the biggest obstacles we have are with faculty. I've met with some faculty who think that just because we are classified as staff that it's almost like we're looked down upon, in a way. Just because we have that staff heading. Also, I mentioned before my manager and my provost have PhDs but the rest of us do not and I think that sometimes with faculty, they look at credentials and just say, "Well, you don't have a PhD so you don't understand. Why am I supposed to listen to what you're doing?" 
It was common for participants without a terminal degree to feel at a disadvantage when establishing an initial relationship with some faculty. Another participant added:

People really listen closely to credentials. If you can't give them the right credentials they won't listen. They don't recognize that we do have advanced degrees in education. Every designer in our department has a master's degree in education.

Teaching experience, both of the faculty and the designer, can influence attitudes toward the value of instructional design collaborations. A participant said:

Well when it comes to faculty, a lot of it is just the acceptance by someone who is outside of their content area may have something valuable to contribute to help them with teaching, especially if it's a faculty member who has been teaching for a very long time. They think, "Oh I've been doing this for so long, how could you possibly not know anything about my subject area and come in and help me learn something about teaching? I've been teaching for 20 or 30 years." These attitudes can result in strained relationships. One participant noted that they faced challenges to debunk notions of some faculty who felt "[instructional design] does not really contribute anything of value, so some people perceive: 'They have more teaching experience than I do, but they're not trained in teaching and pedagogy and those kind of things."” Further, some faculty members' first reaction to a designer was to critique their knowledge and skills. For example, a participant shared:

There was one instructor, he kept e-mailing me articles. "Hey, this research proves that learning styles is a bunch of bologna" and I kept trying to him that just because you may favor one learning style over another doesn't mean you can't learn in a different way. We all learn differently and we all learn different things in different ways. 
Participants who mentioned learning styles further argued that their pedagogical approach was to simply highlight the fact that certain course outcomes may be best accomplished with lectures, hands-on learning, and team activities, not to debate learning theory.

\section{Proving Themselves}

As noted in previous sections of this chapter, there is a thread emerging about the need for the instructional designers to prove themselves. They are tasked with proving themselves as trustworthy, a skilled and useful collaborator, and an expert in teaching in a variety of modalities. Each new project, each new instructor, and each new conversation provides sometimes familiar, sometimes novel, opportunities to prove themselves.

What are some common issues necessitating the call to prove themselves as designers? One of the participants explained, "I think it's been hard because historically faculty didn't ever have a designer. It's a fairly new position." This lack of familiarity with the profession or utility of designers often resulted in a designer feeling a need to prove themselves. In addition, it was often difficult for a designer to assert themselves when faced with faculty members who "...were under the assumption, I guess, that if you were an expert in something you could teach it." Designers described needing to prove their usefulness by offering alternative teaching strategies, or in certain cases, connecting faculty with faculty colleagues, either in their discipline or another, who can model teaching strategies. In doing this, other faculty legitimate the expertise of the instructional designer.

Largely, however, designers have been successful in proving themselves by focusing on teaching without explicitly discussing content. During informal conversations to promote teaching and learning services, one designer noted "we have teaching backgrounds. We have degrees in teaching and you have degrees in your content. If you want to teach that content 
effectively, you need our help." Ultimately, "We just have keep telling people that we're educators first, and we're still ed tech, and ed comes before tech.”

Not only having pedagogical knowledge, but having previous teaching experience was a tremendous asset in proving themselves and garnering respect from faculty. For example, this designer argued,

I think it's very important in the sense that when I go and meet with faculty, I've been in their shoes. I've been the one that's just learning about a new piece of technology, very unsure of how to use it, how it will fit into my teaching style. I think when I lean on that previous experience, I can bring that up with faculty and just let them know that this is something that I've done and I think that that helps when you can talk from personal experiences and feelings. I think that helps build that relationship with faculty when you're meeting with them.

Previous or current teaching experience, or even coming from a previous faculty role, provided a certain sense of legitimacy for the designers. When participants could give examples of how they used particular strategies in their own teaching, it served to prove their usefulness to faculty in the design and delivery of a course.

\section{Faculty Development and Training}

Hosting development and training sessions offers designers the opportunity to showcase a breadth of knowledge as another means to prove themselves. These sessions also create opportunities to develop the necessary relationships that will result in faculty implementing the knowledge and skills developed as a result. How and why faculty find their way to these opportunities varies, as one participant shared, 
There are different triggers that bring people to talk about or think about teaching and learning. Some of those triggers could be that they're going up for a promotion. Another trigger could be that they have bad course evaluations. Another trigger could be that they're new to campus and want to understand more about our students. Another could be concern about technology and wanting to improve there. Another could be they like the stipend that they might get for designing an online course. It might be that the enrollments are low in their department and they think putting it online will increase that. No matter how a faculty member discovered these opportunities, once they did, they typically resulted in a positive outcome. Further, it also served to showcase the competence and expertise instructional designers had, which enhanced trust.

All campuses offered some form of comprehensive online course development services for online courses lasting from 6 weeks to 9 months. Again, these more formal services allow the designer to demonstrate expertise in technology use, curriculum design and alignment, and adapting teaching strategies to an online modality. As I have mentioned previously, these services had multiple and interconnected purposes that allowed designers to prove themselves, minimize misconceptions, and maintain interpersonal relationships.

Participants shared positive feedback from faculty as a result of these training experiences. For example, after one of the more formal, 9-month development opportunities, a faculty member in attendance told his instructional designer that "for the first time in a long time, [he was] thinking about the design of the course, pedagogy and the way he thought about his teaching." This designer not only met the learning outcomes of the training, but also established himself as someone who had something meaningful to contribute to the educational enterprise. 
One subtle but powerful strategy designers used as a way to prove themselves was to create and maintain a focus on teaching that bridges academic units. For example, teaching a large lecture physics course may have similarities with a large lecture biology course. By bringing together faculty from a breadth of academic units, the conversations that ensue, facilitated by the designer, created shared teaching solutions and potential peer-support.

Fostering peer support was an intentional strategy used in training. A participant said, "We did that on purpose, because our campus faculty have long reported that they feel isolated." Another participant went further:

They don't even know what their colleagues are doing in their own department in their courses much less across units. In 2012, we started figuring out, "Okay, do we do one-onone instructional design or do we do it as a group through a program?" We decided to do it as a group as a program because, one, we think sharing experiences among the faculty is a good idea, but also because I think it builds a community and they get to know each other. That's actually some of the feedback that we get mostly, is that not only did they end up with a designed course that's been reviewed, but also they met some great friends and shared ideas and now they have relationships with other people who are teaching online.

More specifically, instructional designers discussed providing course reviews as one consistent service across all campuses. These reviews are of the course structure, curriculum alignment, assessment, and interaction strategies as opposed to reviewing faculty teaching. The designers have no intention of compromising a faculty member's academic freedom, rather they focus on their areas of expertise. In doing so, instructors can better understand the designer's responsibility in their partnership. Ultimately, a designer reported, "we just give 
recommendations and that's all we can do. It's a confidential review, but if it doesn't meet standards, we will highly suggest they make the changes we suggest."

By quickly offering insights and practical utility throughout the services offered often made faculty less resistant. Faculty largely realized that all decisions are ultimately left to the instructor of record. In fact, often just getting instructors to the table was enough to break down barriers. One participant described a successful training;

They didn't really want to hear probably more about objectives and those kinds of things, but it ended up being a really positive experience. I was shocked at how receptive they were. We pulled out the depth of knowledge. They had not seen it before, and they really liked it, and saw how it applied to what they were doing.

Yet, tensions still exist, as a participant lamented regarding course reviews and academic freedom,

We have a rubric and a checklist established by QualityMatters ${ }^{1}$. Well, sometimes the faculty think, "Well, okay. This checklist, you're telling me what I need to have in my course. What gives you the authority that you can do that?" Essentially there, these are national standards and we are doing it for purposes of accreditation that we're tracking the quality of our courses but they don't get that. They just look at the point of, "You're just telling me what needs to be in my course."

Specifically regarding course reviews, participants noted they often use a two-pronged approach guided by their departmental objectives. In one approach, faculty volunteer to have their course reviewed, seeking advice and suggestions on improving their course design. In the second

\footnotetext{
${ }^{1}$ QualityMatters is a national organization focused on quality course design originating at MarylandOnline, Inc. The University of Missouri System campuses are among the over 1,200 member organizations. Additional information is available at https:/www.qualitymatters.org/.
} 
approach, faculty participate as a condition of a course development stipend. With either approach, the intent is to provide valuable insights so that faculty will continue to see instructional designers as a resource for their teaching.

Of those participants who contributed to course reviews, they emphasized the necessity of presenting the review as a collaborative, multidisciplinary effort focused on course design, as opposed to course delivery. Typically, reviews were conducted by a three-member team that included a certified instructional designer; a faculty member from another discipline; and whenever possible, a faculty member from the same discipline as the course. This approach, pioneered by the organization QualityMatters, ensures a sense of rigor and thoughtfulness that allows instructional designers the ability to maintain a position of trust, independence, and a focus on quality course design to enhance student learning.

\section{Place and Space}

For the instructional designers in this study, workspace configuration, and more specifically, proximity to one's team, influenced a sense of professional identity. A majority of participants described a workspace designed around a team approach allowed for deeper collaborations with their fellow designers and technologists. "We plan it as a team, we implement it as a team, we each have different parts. It's not all up to any one of us." Without easy access to colleagues playing various roles in the development process, it is difficult to achieve maximum success. One participant illustrated an ideal office configuration:

Our office set-up is collaborative in nature. It is an open cube farm for most of our team. We have only partial walls and no doors. This is great for collaboration, but we often have to go elsewhere for online meetings, phone calls, consultations, or just a quiet place. However, not everyone is in the office when our best collaboration occurs, so [our 
supervisor] setup a monthly time for us all to commit to being in the office for intentional collaboration. So in addition to reading and discussing an article sent by [our supervisor] on flipped classroom tips, we brainstormed ways to improve our upcoming workshop. Each participant noted the collaborative nature of instructional design, not only with other designers and technologists, but with faculty as well. In addition, exchanging tips and ideas enhanced course development and training sessions and helped the team feel a sense of belonging and identity.

By leveraging a team-based approach, designers ultimately bridge the teaching and technology strategies of collaborating with faculty by improving their own professional competence. Reflecting on the importance of the team-approach among designers, developers, and technologists for their sense of community and collaboration, one participant shared,

I think we definitely are a team-based model. We have a team of instructional designers. We design all of our programs around teams and I feel like I'm a team member with the faculty member with programs that they're putting things on. I'm in it with them.

To further a sense of community among the development team, informal professional development activities can take place in a team-based environment. "Our office passes around the newsletters that we subscribe to, and we each take a turn reading them and passing them off to the next person on the list. These are The Teaching Professor and The Online Classroom." These readings provide opportunities to discuss, as a team, issues and trends in higher education and instructional design. Describing the importance of having a team who can learn from each other, a participant noted,

I think we all have different skill sets that we can lean on when we're trying to, for example, troubleshoot an issue or brainstorm a possible solution for a faculty [university] 
for a long time with a $\mathrm{PhD}$ in education and the wealth of knowledge that she's been able to share has been excellent. That's definitely been extremely beneficial.

Although teams can learn from each other in many ways, having a team-based working configuration makes these exchanges more convenient and spontaneous, and it leverages the breadth of knowledge and experience among team members. Also, it reinforces their sense of belonging and identity as professionals.

\section{Professional Identity}

Further contributing to designers' professional identities was the breadth of services they offered. They varied by campus unit, but whatever the mix of services, it clearly identified the purpose of the unit and of the designers in each campus setting. I explain each of these services below.

Participants reported that, on average, $80 \%$ of the courses on which they are working are considered online or e-Learning. The design process ranged from highly individualized course development with a single instructor to more formal, 10-week cohort-based workshops with faculty from across disciplines geared toward transitioning a face-to-face course to an online format.

Blended courses are different than online courses, as they are typically considered faceto-face courses that use a significant amount of technology in course delivery. Unlike online courses, these support services tended to be more group focused, such as a summer design institute or e-fellows program.

Additional services varied significantly by campus, ranging from collecting mid-semester evaluations, observing classroom teaching, maintaining classroom technology, and supporting 
new faculty orientations and teaching mentoring programs. One outgrowth of supporting online and blended courses are requests by academic units for support in significant curriculum review:

The fact that they [English department] asked us to do that, and it had nothing to do with technology really. It was more about aligning goals, objectives, assessment, course description, all that basic foundational stuff, we thought that was pretty cool that they asked us to do that. Now we have kind of a way of customizing that for a department. We've also recently just last week did one with Chemical Engineering, very similar.

In this example, the English department understood that the instructional design team had a set of pedagogical skills that could benefit them in less typical ways. Further, these collaborations contributed to designer's sense of value and respect in terms of faculty appreciating the breadth of competence designers bring to projects, ultimately reinforcing their professional identity.

\section{Outreach and Promotion of Services}

Whether located within a central instructional design unit or working within a college, a common thread connecting participants was the need to make faculty aware of the scope of services available. As noted earlier, many faculty do not have an idea of what instructional designers do or what utility they provide. One participant, who was the only designer embedded in a particular college, commented "we kind of have to be our own salesmen [sic]." Another participant emphasized one approach, which was to offer customized, one-on-one consultations to tailor services to individual faculty needs:

Building rapport with [faculty], and one person at a time because we used to think we could have these big workshops, and all these people would be converted. That wouldn't happen because, one, not as many people would show up as we thought, and when they did it was just like their classes. You have this huge range of abilities and needs, and you 
cannot meet them all in a larger workshop. I think that we've developed a process that includes a lot more one-on-one. It takes longer, but I think we get better benefits that way.

This quote highlights many of the points already noted throughout the findings: forming bonds and partnerships, proving one's sense, and providing a broad scope of services. Ultimately, this quote speaks to the nature of outreach — how to reach as many faculty as possible. There is a certain scalability in hosting a group of faculty in a single workshop. However, there is utility in customizing consolations one-on-one with faculty. Knowing how to do both is essential to the success of these designers and to establishing their purpose and sense of self within the organization.

Participants noted how their roles are often conflated with their university's information technology division and how that presented challenges in being viewed as a teaching and learning service, rather than computer experts. These misconceptions around instructional design as a primarily pedagogical discipline rather than technology support can erode professional identity. Thus, workshops are necessary in and of themselves to improve pedagogical practices, but also serve as a way to reinforce their professional identity; workshops communicate where instructional designers are placing emphasis: good teaching practice.

Further differentiating themselves from information technology professionals (e.g., the university's Help Desk, System Administration), one participant said, "IT kind of sits and waits for people to come to them. We are out, and about, and interacting with people all the time. We have these relationships." It is worth noting, designers were more focused on establishing and maintaining relationships, whereas instructional technology support tends to be an on-demand service focused on solving discrete technical problems as they arise. To try to address 
misconceptions, designers often framed technology as a tool that can be used in teaching and learning, whereas instructional design reinforces teaching and learning.

My workshops have never felt like [technology] training sessions at all. I never say, "Click here, click there." The way that I frame workshops, in fact, is all about the angle of pedagogy I embed the training in in order to accomplish a learning goal. "Here's how you can use VoiceThread to engage students." I usually do something more specific, but it's about like, "Come learn about VoiceThread." It's like, why should they?

Outreach is essential to demonstrate a designer's active role in the promotion of good teaching and instructional design, and to establish instructional design as a profession focused on maximizing faculty talent, and maintaining ongoing relationships with faculty. One participant described strategies used to promote their professional expertise, noting "[w]e are making videos and we are trying to put new things out on our website to educate people on what we actually do." Such efforts were put in place to advocate how designers offered value to the teaching and learning process and tended to contribute to acceptance and to reinforce professional identity.

Through samples of faculty work, templates, tutorials, newsletters, or blogs, designers, and more generally educational technology units, can increase exposure and provide tangible artifacts of value to instructors. One participant suggested that the maturity of their department offers certain inroads with instructors: “[Faculty] wouldn't use our services, but now that we've been around long enough that they've really seen what we can help with and they understand, then we've gotten a lot more recognition and backing [from faculty and academic units].” Thus, for campuses that are more nascent in terms of instructional design, they may face more barriers and challenges to acceptance. 
The amount of respect that we have built from building enough of a clientele, I guess you could call them, sometimes we call them our repeat offenders, or frequent fliers, those people that have just really bought into teaching and learning with technology. They go and they spread the word about what we can do to help. We have really become so unbelievably busy, and people really value our services, and our insight, and everything that we can do for them.

By leveraging early adopters and other faculty engaged in teaching with technology, it provides a legitimacy with more hesitant faculty.

\section{Demonstrating a Breadth of Knowledge and Professionalism}

In reflecting on their professional identity, participants described themselves as "jack-ofall-trades," "versatile," "a teacher who has an extensive toolbox of other things," those who "help teachers with their teaching and effective technology implementation," and "the answer people." These varied descriptions emphasize that the term instructional design means different things to different people, including faculty, family, and friends. This presents challenges to discovering a sense of professional identity. As an example, one participant remarked, "I'm an instructional designer, and they say, 'well, what exactly does that mean? What do you do?' I basically say, 'well, I kind of teach teachers how to teach.'” One means of mitigating these misconceptions or lack of knowledge was to offer the varied services described in this chapter and ensure that faculty are aware of the varied services through active promotion and outreach.

Another participant shared a story of discussing their job with family members:

Even like my mother, or any of my family members they are: 'What are you doing,' or 'What job did you get? Okay, you're looking at Instructional Design. What does that ...' I tend to just, honestly, gloss over the job title quite often. I'll say, 'Well, I'm working as an 
Instructional Designer, but basically,' and I don't even give them the chance to question what it is because I know they're not going know.

In this particular instance, this participant shared they were a first-generation college graduate and their family had little knowledge of higher education as an enterprise. Although their family had a working understanding of the professoriate, they had no concept of this new managerial elearning professional role, curriculum design, or online learning. Such a reaction is not surprising, given that even those embedded within the educational enterprise (e.g., faculty) have a difficult time fully understanding the instructional design profession, which creates additional challenges to formation of professional identity.

As discussed, participants found themselves having to explain their roles to faculty. One shared, "We just have keep telling people that we're educators first, and we're still ed tech, and ed comes before tech.” Whereas family may not appreciate the nuances of teaching and curriculum, faculty have a working understanding of both so focusing on the teaching provides a common language to begin a working relationship. Another participant continued:

How I describe what I do as my identity as a designer would be that I assist faculty in the development of online courses, is my number one priority, I guess. None of those things ... That on campus, they did not traditionally, a lot of people didn't know what that meant, didn't even know why someone would need help with development of courses. It has been a struggle and I think we're near completely overcoming that struggle to get acceptance that a degree in education is something that's valid and we could help them teach their subject matter that is very specialized, even though we know nothing about that subject matter itself. 
In this section, I have illustrated the emotional and professional demands of identity. When faculty and family cannot describe what you do and who you are, it can make you question your own identity. It can be a tough road both personally and professionally. These challenges can make it that much more difficult to build trust and create partnerships with tenured faculty, teaching faculty, new faculty, or NTT faculty, which are invaluable to the instructional designer's success.

\section{Summary}

This chapter explored the emergent themes presented through the data analysis process. A thread running through these themes is the importance of relationships with faculty and the role they play in developing and maintaining a professional identity. This chapter identified that the primary relationship, the essential relationship, for instructional designers is with faculty. Dispelling misconceptions, maintaining relationships, and promoting an assortment of outreach initiatives focused on teaching practice ultimately provide an opportunity to nurture partnerships and engender trust. All these approaches contribute to a sense of professional identity, a sense of value within higher education, and a role in the university's teaching mission. To make meaning of these findings, in the final chapter, I will answer the research questions through the lens of the framework and will provide recommendations for research and practice in light of these findings.

Prior to doing so, I conclude this chapter with a participant's quote that captures the essence of the participants' experiences, emphasizing the primacy of teaching in the work of instructional design, and the importance of the interpersonal bond instructional designers develop with faculty. 
To me, an instructional designer has two points of their professional identity. To me, one, it's a matter of relationships; and the other one is knowing good academic practice. It's not about the [technology] tools. Tools are changing all the time. 


\section{CHAPTER 5: DISCUSSION}

This study described the lived experiences of a group of academic managerial professionals (i.e., instructional designers) in the corporate university (Rhoades \& Slaughter, 2004; Sandeen, 2014). The principal objective was to understand the ways in which instructional designers negotiate identity in an academic capitalism context — a competitive marketplace_ and maintain interpersonal relationships with faculty. I explored these specific questions: (1) how do instructional designers describe their role within the university?; and (2) how do instructional designers describe their relationship with faculty?

To answer these questions, I relied on activity theory as a theoretical framework to explore the overlapping professional interests of instructional design professionals and the broader higher education culture and actors (Engeström, Engeström, \& Kärkkäinen, 1995). Activity theory examines human action in a social system where professional activity spans organizational and cultural boundaries (Barab, Evans, \& Baek, 2003; Engeström, 1996; Engeström et al., 1995; Podolny \& Baron, 1997). Instructional designers form multiprofessional teams of academic and professional staff who have overlapping and interrelated outputs contributing to the instructional mission of institutions (Barley, 1996; Engeström, 2000, 2004; Whitchurch, 2012; Williams van Rooij, 2011).

Activity theory was especially useful in analyzing complex and overlapping roles, processes, values, and cultures (Patchen \& Smithenry, 2013). Activity theory also calls for those roles and processes to be explicitly identified. For this study, I explored four specific interactive components of activity theory: organizational structures and actors; activities (actions); system conventions and norms; and processes governing interaction (Jarzabkowski, 2003).

Instructional designers are subjects; instructional design, academic capitalism, instructional 
unbundling, and e-Learning are mediating artifacts/processes; and quality instruction is the object. Higher education customs and policies comprise rules for the community, which are comprised of the various stakeholders engaged in disruptive innovation. Faculty and the managerial authority (e.g., supervisors) over instructional designers unbundling determines the division of labor (Engeström, 1999, 2000, 2001).

I found activity theory enhanced the overall approach of this study. The serially interdependent nature of instructional design required a formal, but nuanced theory, to guide inquiry. Norms govern interactions and activities. Structures govern norms and actions. Each facet of the theory informs the other. They overlap like a Venn diagram and instructional designers are uniquely situated at the intersection of the diagram, serving both as buffers and brokers to negotiate and describe these factors.

Regarding data collection, the initial interviews were invaluable in establishing a connection and common purpose with study participants. The calendar annotations and journals provided rich data on the day-to-day work of instructional designers, and allowed for data triangulation. The two participants who submitted more comprehensive journal entries, well beyond the scope of the prompt, included their thoughts and motivations and provided tremendous insights. If I were conducting this study again, I would ask for journals rather than a simple annotated calendar, although I would be concerned that requesting such a time-intensive set of data might discourage participation. The second interview allowed me to ask for clarifications and more details from initial interviews and calendar/journals, allowing for additional ways to achieve confirmability and dependability of the emergent findings.

For the remainder of this chapter, I answer each research question in turn, guided by activity theory. I also highlight how my findings advance the extant scholarship. Next, I 
identify recommendations for future research and practice. Finally, I conclude the study by reflecting on its importance for higher education.

\section{Role of Instructional Designers}

The bounded system of the University of Missouri System is comprised of 4 distinct campuses. Each campus has a unique approach toward instructional design support for faculty ranging from centralized units serving the entire campus community (regardless of teaching modality) to an express focus on e-Learning, or fully online, courses. Further, each of the instructional designers participating in this study described a unique lived experience based on how they arrived to the instructional design profession and configuration of services offered on their campus. Yet, there were patterns and themes that emerged across all of the designers' individual experiences that created the case that I presented in Chapter 4 and the interpretation of that case follows.

Instructional designers, Whitchurch (2012) noted, bring a "depth of knowledge and broader transdisciplinary knowledge and skills (p. 103). All instructional designers participating in this study held post-baccalaureate degrees although these range from instructional designspecific degrees to some other disciplinary focus such as biology. Participants reported coming to the instructional design profession through three principal paths: experience in K-12 education, experience in higher education, or an interest and expertise in instructional technology.

\section{Activities}

Academic managers set priorities and policies within the units where instructional designers work. These priorities enhanced a sense of professional identity based on the breadth of services provided to the academic community. Instructional designers described a breadth of 
activities, both formal and informal. Formal activities ranged from online course development, cohort and one-on-one professional development sessions and training with faculty, in-person classroom observations, and course quality reviews. Some participants also described a broader set of responsibilities that included support of classroom-based courses and other teaching and learning support such as classroom observations that enhanced their sense of professional identity. Less formal activities, albeit related to completion of their duties, included maintaining positive relationships with faculty and advancing good, effective teaching practice.

All of these activities support the institutional pressures to increase enrollments and student access to higher education. Ultimately, with an eye toward revenue generation, academic capitalism and instructional unbundling require a team of experts (i.e., faculty, instructional designers, technologists, marketing professionals) to facilitate an expansion into the online marketplace (Christensen, 1997, 2006; Deem, 2001; Olivas, 2004; Wolff, 2010). In these ways, the instructional designer acts as a buffer because they essentially serve as project manager for the timely and coordinated delivery of online courses and programs.

\section{Factors Governing Interactions}

A principal norm governing faculty throughout U.S. higher education is that of the academic freedom. One of the more challenging and sensitive issues instructional designers described was related to academic freedom. Based on findings, these challenges most often developed because many faculty were unfamiliar with the work and profession of instructional designers. This often led to initial misconceptions especially with the intersecting disruptive innovations of accountability, quality assurance, and massification.

Another factor that governed system conventions and norms was based on how some faculty conceptualized the notion of expertise and being an expert. Participants noted repeatedly 
that even if they had a $\mathrm{PhD}$, they were often perceived as having legitimate expertise. This played out more often in the hard sciences and engineering. For example, if the designer had a $\mathrm{PhD}$ in a social science, a faculty member in engineering discounted the degree and would have valued it more if it was more closely aligned with the faculty member's discipline. However, participants did note that if they had teaching experiences in higher education, a fundamental part of faculty work, they garnered more trust and respect from faculty.

A significant factor in evolving processes in course planning, development, and delivery is instructional unbundling where there are multiple, discrete, serially-interdependent actions between faculty and instructional designers (Whitchurch, 2010). In this study, faculty provide the content expertise while instructional designers provide expertise in the e-Learning delivery space. This new professional working paradigm goes to the heart of creating and maintaining relationships. If the designer is seen to contribute value to the development and delivery of online courses in particular, faculty are reported to be more willing to establish partnerships, accepting advice, and considering new approaches to content delivery.

Lastly, a factor that sometimes governed interactions between the instructional designers and faculty was the perceived internal conflict faculty felt about contributing to the academic mission and the institutional push toward increased revenue generation via online and distance education. Faculty join the professoriate to teach, research, and provide service to the community (AAUP, 2010; Coates \& Goedegeburre, 2012; Nyquist et al., 1999) so for some, accepting the assistance of an instructional designer to deliver on an academic capitalist agenda can create resistance (Christensen, 1997, 2006; Rhoades, 1996). As a strategy, designers focused on quality course design and delivery to mitigate concerns over simply trying to "make money."

\section{Relationships with Faculty}


Participants discussed their relationships with faculty throughout their interviews. Most partnerships developed when a faculty member identified a teaching intervention that was needed. Then, the instructional designer and faculty member developed a solution, selected an appropriate teaching strategy, and implemented the required technological intervention.

In addition, when reviewing their annotated calendars, interactions with faculty comprised the most of their work week. Participants' annotated calendars highlighted their roles as both buffers and brokers with faculty. Buffers and brokers facilitate a "serially interdependent occupational division of labor," negotiating boundaries and priorities of managers and faculty (Barley, 1996, p. 420). Instructional designers often mitigated conflict within the academic community and bridged constituencies as a hybrid of managers and faculty, belonging in both and in neither world as insiders and outsiders (Levin \& Shaker, 2011). Since instructional designers have many hats, and serve as buffers and bridges between several constituencies in an academic capitalism context (administration, managers, etc.) they need to advance e-Learning acceptance while respecting the role of faculty specifically. From negotiating with internal partners in online course programming, updating copyright standards and procedures, writing procurement justifications for new student software, coordinating with textbook publishers for eresources, facilitating lecture transcription services, designers bridged faculty, technology services, outside vendors, and other internal constituencies.

Approaching work with faculty members also required a level of flexibility and adaptability on the part of the instructional designer. Whether it be a formal, sustained course development process or in-office consultation, providing faculty with a breadth of options was found to engender trust. As noted in the previous chapter, time can be a barrier to collaboration 
and relationship formation so finding the right mix of services can mitigate this as a challenge to facilitating instructional unbundling.

Close working relationships fostered networking and engendering faculty confidence in instructional designers. Those relationships also served to extend the reach of these professionals with an expanding population of faculty interested in teaching development and support. Most often, this manifested during teaching consultations on, for example, planning a student presentation assignment for an online course. That consultation would naturally develop into a show-and-tell for how to use a specific software to allow students to record their presentation.

\section{Recommendations for Future Research}

I offer four specific recommendations for future research. One, given the experience of the designers described in this study, is there a difference in the formation and maintenance of professional identity and relationships if an instructional designer is assigned to specific faculty versus working as more of a campus generalist? This was outside the course of this study but additional research may offer insights into the efficacy of imbedded designers. Second, I found that although instructional designers held the same job title, their roles varied greatly. Research should seek to answer how variations in job descriptions and departmental expectations influence identity formation and maintenance. Third, instructional designers come to the profession with divergent backgrounds and distinct credentialing. Conducting a multiple case study with crosscase analysis could uncover what influence these backgrounds have on professional identity.

Lastly, I collected data for this study during the 2016-2017 academic year. Given the complete shift to online learning during the 2020 pandemic, future research should examine how relationships with faculty changed, particularly for those who have never taught online but had 
no choice to do so because campuses cancelled in-person learning to protect the health and safety of the university community. Participants in the study typically worked with faculty on a voluntary basis who expressed an interest in enhancing their classroom teaching with technology, gaining expertise in new teaching methods, or teaching a fully online course. With fewer than 20 dedicated instructional designers on these four campuses, how has the pandemic reshaped their identities? How has the changing demand to their workload to scale-up to serve thousands of faculty almost immediately influenced how faculty and institutional leadership perceive these essential professionals? Further, what will be the long-term effects of the pandemic to course delivery and to the roles that instructional designers play?

\section{Recommendations for Practice}

Activity theory provided insights into the overlapping and serial workflow in a higher education, instructionally unbundled context. Actor motivations and customs play a particular role in understanding this context. Providing not only professional development opportunities, but also socialization of faculty, across disciplines may create a community of teachers - those who deliver instruction to students in a variety of modalities. Professional development opportunities specifically cited by participants included becoming certified as QualityMatters course reviewers and receiving online teaching certification from the Online Learning Consortium for both faculty and designers (Fumasoli \& Stensaker, 2013; Hardre \& Chen, 2008; Rhoades, 2001; Sandeen, 2014; Smith, 2008). For academic managers, investing resources in these opportunities enhance not only the professional identity of instructional designers, but the quality of the work they do. And lastly, if institutions are committed to massify and expand eLearning courses and programs (Alexander, 2000; Austin, 2002; Brooks \& Miles, 2010; Doyle, 2010; Lewis \& Fisarelli, 2010; Robst, 2000; Sandeen, 2014; Steck, 2003; Szekeres, 2004; Wood, 
2013), clear policies regarding academic freedom and intellectual property are essential. Several participants specifically mentioned the challenge of making faculty aware of existing, stated policies at the University of Missouri System regarding intellectual property, suggesting that more transparency is needed among faculty regarding these policies. Moreover, as technology continues to evolve, these policies must be reviewed regularly to ensure that they address the current context.

For the University of Missouri System, changing or amplifying policies that govern online learning and massification is delicate. The University of Missouri System, as an organization, is an administrative body. The campuses offer courses, have academic programs and faculty, develop curricula, and enroll students. The system establishes organizational goals and macro-policies, such as intellectual property policies. Steering a ship with four very different campuses should be approached with transparency, communication, and collaboration among a broad array of constituencies including faculty, managerial professionals, and administrators. Managing deep change in course delivery to facilitate revenue generation, a principal motivation of academic capitalism (Christensen, 1997, 2006; Deem, 2001; Olivas, 2004; Rhoades, 1996; Wolff, 2010), requires deft negotiation of all these constituencies.

Finally, this study warrants recommendations for my profession, the instructional design profession. Instructional designers must remember that relationships matter. Their institution matters, as does their scope of services. Focusing on good, quality teaching and course delivery matters. A support network of other instructional designers, either on their own campus or another campus, matters. As I have noted throughout this study, instructional designers often operate "in the shadows," so they may have to remind people what it is they do. Although, with the forced changes in instruction due to the pandemic, which has demonstrated the invaluable 
role instructional designers can play, perhaps this will become less of a burden. Instructional designers should keep up the good work because they are contributing to many of the promises of higher education.

\section{Conclusion}

Instructional designers and other managerial professionals have become essential to instructional unbundling (Fumasoli \& Stensaker, 2013; Hardre \& Chen, 2008; Rhoades, 2001; Sandeen, 2014; Smith, 2008), a dramatic shift toward using online programs to attract net-new student enrollments to generate revenue, and provide access to higher education for students (Christensen, 1997, 2006). Assisting faculty, who are content experts with classroom teaching experience, to effectively adapt their teaching approaches and content delivery to an online modality is critical to student learning and satisfaction (Fyle, Moseley, \& Haynes, 2012; Herman, 2012). Although the theory of academic capitalism is essentially a critique of the commercialization of higher education (Horkheimer, as cited in Kivisto, 2011; Leonardo, 2004; Slaughter \& Rhoades, 2004), the reality of instructional unbundling exists and instructional designers serve a meaningful purpose in delivering on quality course design, and delivery (Fumasoli \& Stensaker, 2013; Hardre \& Chen, 2008; Rhoades, 2001; Sandeen, 2014; Smith, 2008). Appreciating the professional identity of these multidisciplinary teams of managerial professionals allows the academy to best leverage the talents and strengths of team members for the common purpose of quality higher education (Barab et al., 2003; Barley, 1996; Szekeres, 2004, 2006). 


\section{Appendix A}

\section{Participant Invitation}

\section{Dear [Participant Name]:}

I am a doctoral student in the Department of Educational Leadership and Policy Analysis at MU conducting a dissertation study. The purpose of my study is to better understand professional identity development of instructional designers. Your participation in this study would greatly enhance my understanding of the instructional design profession. According to the University of Missouri public directory, you are an instructional designer.

Participation involves three deliverables:

1. The initial interview will last no more than 1 hour and explore your professional identify, working environment and relationships, and describe various aspects of your demographics.

2. Following our initial interview, I will ask you to annotate a copy of your professional calendar over 1 month. Annotations will capture your experiences and observations of working in instructional design, higher education, and working relationships with administrators and faculty. Annotated calendars will be submitted to me via Box.

3. The second interview will last no more than 1 hour and provide an opportunity to discuss your journaling experience.

If you are willing to participate, please respond to this email by DATE, and I will work with you to find a mutually convenient time, location, and modality for the interview. Participation is completely voluntary and you can withdraw at any time during the study, but I do hope you will help me with this project.

Thank you in advance for your willingness to consider participating in this research. Complete consent information is found attached to this e-mail.

Sincerely,

Matthew Livengood 


\title{
Appendix B
}

\author{
Managerial e-Learning Professionals Dissertation Study \\ Informed Consent
}

This form requests your consent to participate in a research study that explores the professional identity of instructional designers. The project is part of a dissertation study. Data collection and analyses will be completed under the direction of Dr. Jennifer (Jeni) L. Hart, Associate Professor and Associate Division Director, Department of Educational Leadership and Policy Analysis. Each of two interviews will take approximately one hour; calendar annotations should take no longer than 1 hour in total.

Project description: This research project involves two interviews with working instructional designers to explore professionalism and identity. Additionally, a brief annotated participant calendar will be generated over a working month.

Potential Benefits and Concerns: Findings of this project will be integrated into reports, presentations, and publications that can advance the scholarship of managerial professionals and academic capitalism. Findings may also be used in articles, presentations, and other publications to inform a national and international audience.

Confidentiality: In accordance with MU policy, the research materials will be kept on a password protected computer for a period of 7 years after the completion of the research project. All information associated with project participants will be kept in a locked office accessible only to the researcher. Findings will be presented in a written dissertation study, presentations, and research articles. Pseudonyms will be used and other identifiers excluded from reports and presentations.

Audio recording: All interviews will be audio recorded (audio/video recorded in the case of a web-based video conference), unless you prefer to have the interview conducted without recording. If you agree to have the interview recorded, you have the right to request the recorder be stopped at any time - either to stop the interview completely or to continue the interview unrecorded.

Participation is Voluntary: Your participation is entirely voluntary, and you can decline to answer any questions you do not wish to or withdraw your participation in this study at any time without penalty. You can freely withdraw from the project at any time without negative consequences, and all data pertaining to you will be destroyed.

Questions: Please contact Matthew Livengood (573-882-3139; livengoodclousem@missouri.edu) or Dr. Jeni Hart (573-882-8221; hartj1@missouri.edu) with any questions or concerns. If you have questions about your rights as a research project participant, you may contact the MU Institutional Review Board at $573-882-9585$. 


\section{Appendix C \\ Semi-Structured Initial Interview Protocol}

- Describe your career trajectory that led to your current role as an instructional designer.

- How long have you been an instructional designer (experience)? At this institution?

- How has your position changed over time?

- What educational experiences prepared you for instructional design (credential)?

- How were you prepared to work in higher education?

- How often do you interact with faculty?

- Provide a recent example of an interaction with a faculty member.

- How often do you interact with your manager and/or other campus administrators who may guide your agenda and goals?

- Describe your relationships with others in the workplace.

- How do you sustain these relationships?

- Describe your professional identity.

- How do you maintain professional identity in the workplace?

- Describe your workplace climate.

- Describe any barriers to collaboration you have experienced.

- Describe a typical day in your position as an instructional designer. 


\section{Appendix D}

\section{Semi-Structured Participant Calendar Annotation Protocol}

Over the course of 1 working month, please generate an annotated calendar and submit the text to the researcher.

Annotations may include (but are not limited to):

- Observations of your working environment and social structures

- Summary of professional outputs (e.g., curriculum products, technology training)

- The nature and frequency of professional interactions with faculty

- General reflections on maintaining and developing professional identity

- Opportunities and strategies for relationship maintenance

- Barriers or difficulties in collaborating with faculty 


\section{Appendix E}

\section{Semi-Structured Second Interview Protocol}

- In your journaling, you mention professional interactions and outputs. Tell me more about your interactions with certain faculty.

- How did you develop a certain strategy for maintaining interpersonal relationships in the workplace?

- How have certain professional outputs influenced your professional identity in the workplace?

- Tell me more about your workplace climate.

- Tell me more about a certain barrier to collaboration you experienced. 


\section{References}

Allen, E., \& Seaman, J. (2011). Going the distance: Online learning in the United States. Retrieved from http://sloanconsortium.org/publications/surveys

Alexander, F. K. (2000). The changing face of accountability: Monitoring and assessing institutional performance in higher education. The Journal of Higher Education, 71(4), $411-431$

Almala, A. (2005). A constructivist conceptual framework for a quality e-Learning environment. Distance Learning, 2(5), 9-12.

Amaral, A. (2013). The difficult life of prophets and seers. Higher Education Policy, 26, 463-478. doi:10.1057/hep.2013.29

Amory, A. (2012). Instructivist ideology: education technology embracing the past? Interactive Learning Environments, 20(1), 41-55. doi:10.1080/10494821003714707

Anfara, V. A., Brown, K. M., \& Mangoine, T. L. (2002). Qualitative analysis on stage: Making the research process more public. Educational Researcher, 31(7), 28-38.

Anyon, J. (2009). Theory and educational research: Toward critical social explanation. New York, NY: Routledge.

Aten, K., Howard-Grenville, J., \& Ventresca, M. J. (2012). Organizational culture and institutional theory: A conversation at the border. Journal of Management Inquiry, 21(1), p. 78-83. doi: $10.1177 / 1056492611419790$

Austin, A. (2002). Preparing the next generation of faculty. Journal of Higher Education, 73(1), 94-122.

Baiyun, C. (2009). Barriers to adoption of technology-mediated distance education in highereducation institutions. Quarterly Review of Distance Education, 10(4), 333-338. 
Barab, S. A., Evans, M. A., \& Baek, E. (2003). Activity theory as a lens for characterizing the participatory unit. In D. H. Jonassen (2nd ed), Handbook of research for educational communications and technology (pp. 199-214). New York, NY: Simon and Schuster Macmillan.

Baran, E., Correia, A., \& Thompson, A. (2011). Transforming online teaching practice: critical analysis of the literature on the roles and competencies of online teachers. Distance Education, 32(3), 421-439.

Barley, S. R. (1996). Technicians in the workplace: Ethnographic evidence for bringing work into organizational studies. Administrative Science Quarterly, 41(3), 404-441. doi: $10.1177 / 09500170222119245$

Baruch, Y. (2004). Transforming careers: from linear to multidirectional career paths. Career Development International, 9(1), 58-73.

Beiber, J. P., \& Worley, L. K. (2006). Conceptualizing the academic life: Graduate students’ perspectives. Journal of Higher Education, 77(6), 1009-1035.

Berente, N., \& Yoo, Y. (2012). Institutional contradictions and loose coupling: Postimplementation of NASA's enterprise information system. Information Systems Research, 23(2), 376-396.

Birnbaum, R. (1988). How colleges work: The cybernetics of academic organization and leadership. San Francisco, CA: Jossey-Bass.

Blackler, F. (1993). Knowledge and the theory of organizations: Organizations as activity systems and the reframing of management. Journal of Management Studies, 30(6), 863884.

Blackmore, J. (2001). Universities in crisis? Knowledge economies, emancipatory pedagogies 
and the critical intellectual. Educational Theory, 51(3), 353-370.

Bogdan, R. C., \& Biklen, S. (2007). Qualitative research for education: An introduction to theory and methods. Needham Heights, MA: Allyn \& Bacon.

Bolden, R., Petrov, G., \& Gosling, J. (2008). Tensions in Higher Education Leadership: Towards a multi-level model of leadership practice. Higher Education Quarterly, 62(4), 358-76.

Bott, E. (2010). Favourites and others: reflexivity and the shaping of subjectivities and data in qualitative research. Qualitative Research, 10(2), 159-173.

Boeije, H. (2002). A purposeful approach to the constant comparative method in the analysis of qualitative interviews. Quality \& Quantity, 36, 391-409.

Bratianu, C., \& Stanciu, S. (2010). An Overview of present research related to entrepreneurial university. Management \& Marketing, 5(2), 117-134.

Brewer, J. D. (2000). Ethnography. Philadelphia, PA: Open University Press.

Brooks, J. S., \& Miles, M. T. (2010). Educational leadership and the shaping of school culture: Classic concepts and cutting-edge possibilities. In S. D. Horsford (Ed.), New perspectives in educational leadership (pp. 7-28). New York, NY: Peter Lang.

Calvert, M., Lewis, T., \& Spindler, J. (2011). Negotiating professional identities in higher education: Dilemmas and priorities of academic staff. Research in Education, 86(1), 2538.

Campbell, K., Schwier, R., \& Kenny, R. (2007). The critical, relational practice of instructional design in higher education: An emerging model of change agency. Educational Technology Research \& Development, 57(5), 645-663.

Carroll, C., Booth, A., Leaviss, J., \& Rick, J. (2013). "Best fit” framework synthesis: Refining the method. BMC Medical Research Methodology, 13(37). doi:10.1186/1471-2288-13-37 
Caulley, D.N. (2008). Making qualitative research reports less boring: the techniques of writing creative nonfiction. Qualitative Inquiry, 14(3), 424-450.

Carter, S., Sturm, S., \& Gonzales Geraldo, J.L. (2014). Situating e-learning: Accelerating precepts from the past. International Journal of Pedagogies and Learning, 9(1), 1-9.

Cheslock, J. J. (2006). Applying economics to institutional research on higher education revenues. New Directions for Institutional Research, 132, 25-42.

Chow, A. (2013). One educational technology colleague's journey from dotcom leadership to university e-Learning systems leadership: Merging design principles, systemic change and leadership thinking. Techtrends: Linking Research \& Practice to Improve Learning, 57(5), 64-73.

Christensen, C. (1997). The innovator's dilemma: When new technologies cause great firms to fail. Boston, MA: Harvard Business School.

Christensen, C. (2006). The ongoing process of building a theory of disruption. The Journal of Product Innovation and Management, 23, 39-55.

Christensen, T.K., \& Osguthorpe, Russell T. (2004). How do instructional-design practitioners make instructional-strategy decisions? Performance Improvement Quarterly, 17(3), 4565.

Chronicle of Higher Education (2010). Missouri Almanac. Retrieved from http://chronicle.com/article/Missouri-Almanac-2010/124041/

Coates, H., \& Goedegeburre, L. (2012). Recasting the academic workforce: why the attractiveness of the academic profession needs to be increased and eight possible strategies for how to go about this from an Australian perspective. Higher Education, 64(6), 875-889. 
Coffman, S. (2011). "A social constructionist view of issues confronting first-generation college students" in Housel, H., \& Housel, T.H. (2011). Faculty and first-generation college students: Bridging the classroom gap together. San Francisco, CA: Jossey-Bass.

Collins, R. (1971). Functional and conflict theories of educational stratification. American Sociological Review, 36(6), 1002-1019.

Colyar, J. (2009). Becoming writing, becoming writers. Qualitative Enquiry, 15, 421-436.

Coo, J., \& Trent, A. (2006). Validity in qualitative research revisited. Qualitative Research, 6(3) $319-340$.

Coser, L. (2011). The functions of social conflict. In Kivisto, Social Theory: Roots and Branches, Fourth Edition (pp. 216-219). New York, NY: Oxford University Press. (Reprinted from The Functions of Social Conflict by Lewis Coser, 1984).

Courant, N., McPherson, M., \& Resch, A. M. (2006). The public role in higher education. National Tax Journal, 59(2), 291-318.

Cox, S., \& Osguthorpe, R. T. (2003, May / June). How do instructional design professionals spend their time? TechTrends, 47(3), 45-47.

Craig, R., Amernic, J., \& Tourish, D. (2014). Perverse audit culture and accountability of the modern public university. Financial Accountability \& Management, 30(1), 1-33.

Creswell, J.W. (2009). Research design: Quantitative, qualitative, and mixed methods approaches $\left(3^{\text {rd }}\right.$ ed.). Thousand Oaks, CA: Sage.

Crotty, M. (1998). The Foundations of Social Research. London: Sage.

Daniels, H. (2007). Discourse and identity in cultural-historical activity theory: A Response. International Journal of Educational Research, 46, 94-99.

Deem, R. (2001). Globalisation, new managerialism, academic capitalism and entrepreneurialism 
in universities: is the local dimension still important? Comparative Education, 37(1), p720.

Demps, E. L., Lincoln, Y.S., \& Cifuentes, L. (2011). Conflicts over the utilities of teaching using educational technologies: An interpretive critical inquiry. Advances in Developing Human Resources, 13(2), 135-170. doi: 10.1177/1523422311415641

Dobson, I., \& Conway, M. (2003). Fear and loathing in university staffing: The case of Australian academic and general staff. Journal of Higher Education Management and Policy, 15(3): 123-134.

Domas White, M., \& Marsh, E. E. (2006). Content analysis: A flexible methodology. Library trends, 55(1), 22-45.

Doyle, W.R. (2010). Does merit-based aid "crowd out" need based aid? Research in Higher Education, 51(5), 397-415.

Dressman, M. (2008). Using social theory in education research. New York, NY: Taylor \& Francis.

Ebert-May, D., Derting, T.L., Hodder, J., Momsen, J.L., Long, T.M., \& Jardeleza, S.E. (2011). What we say is not what we do: Effective evaluation of faculty professional development programs. BioScience, 61, 550-558.

Ehrenberg, R. G. (2006). The perfect storm and the privatization of higher education. Change, $38,46-51$.

Enders, J. (2005). Border crossings: research training, knowledge dissemination and the transformation of academic work. Higher Education, 49(1/2), 119-133.

Enders, J., \& de Weert, E. (2009). The Changing Face of Academic Life: Analytical and Comparative Perspectives. Palgrave Macmillan. 
Engeström, Y. (1999). Innovative learning in work teams. In Y. Engeström, R. Miettinen \& R.

L. Punamäki (Eds.), Perspectives on activity theory (pp. 377-404). New York, NY:

Cambridge University Press.

Engeström, Y. (2000). Activity theory as a framework for analyzing and redesigning work. Ergonomics, 43, 960-974.

Engeström, Y. (2001). Expansive learning at work: Toward an activity theoretical reconceptualization. Journal of Education and Work, 14, 133-156.

Engeström, Y. (2004). New forms of learning in co-configuration work. Journal of Workplace Learning, 16(1/2), 11-21.

Engeström, Y., Engeström, R., \& Kärkkäinen, M. (1995). Polycontextuality and boundary crossing in expert cognition: Learning and problem solving in complex work activities. Learning and Instruction, 5, 319-336.

Erlandson, D., Harris, E., Skipper, B., \& Allen, S. (1993). Doing naturalistic inquiry: A guide to methods. Newbury Park, CA: Sage.

Fumasoli, T., \& Stensaker, B. (2013). Organizational studies in higher education: A reflection on historical themes and prospective trends. Higher Education Policy, 26, 479-496.

Fyle, C. O., Moseley, A., \& Hayes, N. (2012). Troubled times: the role of instructional design in a modern dual-mode university? Open Learning: The Journal of Open, Distance and eLearning, 27(1), 53-64.

Garud, R., Hardy, C., \& Maguire, S. (2007). Institutional entrepreneurship as embedded agency: An introduction to the special issue. Organization Studies, 28, 957-969. doi: $10.1177 / 0170840607078958$

Glaser, B. G., \& Strauss, A. L. (1967). The discovery of grounded theory: Strategies for 
qualitative research. Chicago, IL: Aldine.

Green, R. (2003). Markets, management, and "reengineering" higher education. Annals of the American Academy of Political and Social Science, 585, 196-210.

Gurr, D. (2004). ICT, leadership in education and e-leadership. Discourse: Studies in the cultural politics of education, 25(1), 113-124.

Hall, P.M. (2003). Interactionism, social organization and social processes: looking back and moving ahead. Symbolic Interaction, 26(1), p33-55. doi: 10.1525/si.2003.26.1.33

Hardre, P.L., \& Chen, C-H. (2008). A case study analysis of the role of instructional design in the development of teaching expertise. Performance Improvement Quarterly, 18(1), 3458. doi: 10.1111/j.1937-8327.2005.tb00325.x

Harklau, L., \& Norwood, R. (2001). Negotiating researcher roles in ethnographic program evaluation: A postmodern lens. Anthropology and Education Quarterly, 36(3), 278-288.

Heeyoung Han, H., Kuchinke, K. P., \& Boulay, D. A. (2009). Postmodernism and HRD theory: Current status and prospects. Human Resource Development Review, 8, 54-67. doi:10.1177/1534484308330021

Herman, J. (2012). Faculty development programs: The frequency and variety of professional development programs available to online instructors. Journal of Asynchronous Learning Networks, 16(5): 87-106.

Hoffman, S. G. (2011). The new tools of the science trade: contested knowledge production and the conceptual vocabularies of academic capitalism. Social Anthropology, 19(4), 439462. doi: $10.1111 / j .1469-8676.2011 .00180 . x$

Hora, M. T. (2014). Exploring Faculty Beliefs about Student Learning and Their Role in Instructional Decision-Making. The Review of Higher Education, 38(1), 37-70. 
Jarzabkowski, P. (2003). Strategic practices: An activity theory perspective on continuity and change. Journal of Management Studies, 40(1), 23-55.

Jaschik, S., \& Lederman, D. (2014). The 2014 Inside Higher Ed survey of faculty attitudes on technology. Washington, DC: Gallup, Inc. Retrieved from the Inside Higher Ed website: https://www.insidehighered.com/news/survey/online-ed-skepticism-and-selfsufficiency-survey-faculty-views-technology

Johnson, D. R. (2012). Technological change and professional control in the professoriate. Science, Technology, \& Human Values, 38(1), 126-149. doi: 10.1177/0162243911430236

Johnstone, D. B., \& Marcucci, N. (2007). Worldwide trends in higher education finance: Cost-sharing, student loans, and the support of academic research. Paper presented to UNESCO Forum on Higher Education, Research, and Knowledge.

Johnson, R. B., \& Onwuegbuzie, A. J. (2004). Mixed methods research: A research paradigm whose time has come. Educational Researcher, 33(7), 14-26.

Kanuka, H., Jugdev, K., Heller, R., \& West, D. (2007). The rise of the teleworker: false promises and responsive solutions. Higher Education, 56, 149-165. doi: 10.1007/s10734007-9095-z

Kavanagh, D. (2009). Institutional heterogeneity and change: the university as fool. Organization, 16, 575-595. doi: 10.1177/1350508409104509

Kezar, A. J., \& Eckel, D. (2002). The effect of institutional culture on change strategies in higher education: Universal principles or culturally responsive concepts. The Journal of Higher Education, 73(4), 435-460.

Kirshstein, R. J., \& Hurlburt, S. (2012). Revenues: Where does the money come from? A Delta data updated 2000-2010. Retrieved from Delta Cost Project at American Institutes for 
Research website: http://www.deltacostproject.org/pdfs/Revenue_Trends_Production.pdf

Kiyama, J. M, Lee, J .J., \& Rhoades, G. (2012). A critical agency network model for building an integrated outreach program. The Journal of Higher Education. 83(2), 276-303.

Kivisto, (2011). Social Theory: Roots and Branches, Fourth Edition. New York, NY: Oxford University Press.

Kriger, T. J., \& Scheuerman, W. E. (2000). Edubusiness comes to the academy: The virtual university and the threat to academic labor. Working USA, 4(2), 1-39.

Leslie, L. L., \& Rhoades, G. (1995). Rising administrative costs: Seeking explanations. Journal of Higher Education, 66(2), 187-212.

Levin, J. S., \& Shaker, G. G. (2011). The hybrid and dualistic identity of full-time non-tenuretrack faculty. American Behavioral Scientist, 55: 1461-1484. doi: $10.1177 / 0002764211409382$

Lewis, M. W., \& Grimes, A. J. (1999). Metatriangulation: building theory from multiple paradigms. The Academy of Management Review, 24(4), p672-690.

Leonardo, Z. (2004). Critical social theory and transformative knowledge: The functions of criticism in quality education. Educational Researcher, 33(6), $11-18$.

Lincoln, Y. S., \& Guba, E. G. (1985). Naturalistic inquiry. Beverly Hills, CA: Sage.

Lounsbury, M., \& Crumley, E. T. (2007). New practice creation: An institutional approach to innovation. Organization Studies, 28, 993-1012.

MacIntosh, R., \& MacLean, D. (1999). Conditioned emergence: a dissipative structures approach to transformation. Strategic Management Journal, 20(4), 297-316.

Marek, K. (2009). Learning to teach online: Creating a culture of support for faculty. Journal 
of Education for Library and Information Science, 50(4), 275-292.

Mars, M., \& Ginter, M. (2012). Academic innovation and autonomy: an exploration of entrepreneurship education within American community colleges and the academic capitalist context. Community College Review, 40(75). doi: 10.1177/0091552111436209

Mars, M. M., \& Rhoades, G. (2012). Socially-oriented student entrepreneurship: A study of student change agency in the academic capitalism context. The Journal of Higher Education, 83(3), 435-459.

McGinty, J. W. (2014), Divided and drifting: Interactionism and the neglect of social organizational analyses in organization studies. Symbolic Interaction, 37(2), 155-186.

McLendon, M. K., \& Eddings, S. (2002). Direct democracy and higher education: The state ballot as an instrument of higher education policy making. Educational Policy, 16(1), 193-218.

Mendoza, (2008). Socialization to the academic culture: a framework of inquiry. Revista De Estudios Sociales, 31, 104-117.

Mendoza, P., Kuntz, A. M., \& Berger. J. B. (2012). Bourdieu and academic capitalism: Faculty "habitus" in materials science and engineering. The Journal of Higher Education, 83(4): $558-581$.

Merriam, S. B. (2009). Qualitative research: A guide to design and implementation ( $2^{\text {nd }}$ ed.). San Francisco, CA: Jossey-Bass.

Metcalfe, A. (2006). The corporate partners of higher education associations: A social network analysis. Industry and Innovation, 13(4): 459-479.

Miles, M., \& Huberman, A. M. (1994). Qualitative Data Analysis. Thousand Oaks, CA: Sage. 
Missourian (2018). UM System wants 25,000 enrollment boost by 2023, says e-

learning is key. Retrieved from

https://www.columbiamissourian.com/news/higher_education/um-system-wantsenrollment-boost-by-says-e-learning-is/article_69ced8b6-e91e-11e8-b1dd4f2247e4df90.html

MizzouOnline (2014). MizzouOnline Enrollment Report. Available online http://online.missouri.edu/pdf/2013-14-Mizzou-Online-Enrollment-Report.pdf

Moore, M., \& Kearsley, G. (2012). Distance education: A systems view of online learning. Belmont, CA: Wadsworth.

Mumford, T. V., Van Iddekinge, C. H., Morgeson, F. P., \& Campion, M. A. (2008). The team role test: Development and validation of a team role knowledge situational judgment test. Journal of Applied Psychology, 93, 250-267.

Morrill, C. (2008). Culture and organization theory. Annals of the American Academy of Political and Social Science, 619, 15-40.

Neely, P., \& Tucker, J. (2010). Unbundling faculty roles in online distance education programs. Contemporary Issues in Education Research, 3(6), 17-23. Retrieved October 5, 2010, from ABI/INFORM Global. (Document ID: 2065702281).

Nolen, A., \& Talbert, T. (2011). Qualitative assertions as prescriptive statements. Educational Psychology Review, 23, 263-271.

Nyquist, J. D., Manning, L., Wulff, D. H., Austin, A. E., Sprague, J., Fraser, K., Calcagno, C., \& Woodford, B. (1999). On the road to becoming a professor: The graduate Student experience. Change, 31(3), 18-27.

Olivas, M. A. (2004). The rise of nonlegal legal influences in higher education. In R. G. 
Ehrenberg (Ed.), Governing academia (pp. 258-275). Ithaca, NY: Cornell University.

Oplatka, I. (2014). Differentiating the scholarly identity of educational administration: An epistemological comparison of two neighboring fields of study. Journal of Educational Administration, 52(1), 116 - 136. doi: 10.1108/JEA-12-2012-0137

Parish, B. (2013). “Appropriate” technology. Inside Higher Education. Retrieved from http://www.insidehighered.com/views/2013/05/02/technology-innovation-should-focusletting-teachers-teach-essay

Pastore, R., \& Carr-Chellman, A. (2009). Motivations for residential students to participate in online courses. Quarterly Review of Distance Education, 10(3), 263-277.

Patchen, T., \& Smithenry, D.W. (2013). Diversifying instruction and diversifying authority: A cultural historical activity theory (CHAT) analysis of classroom participation structures. Journal of Research in Science Teaching, 51(5), 606-634.

Plater, W. M. (2008). The twenty-first century professoriate. Academe, 94(4), 35-40.

Podolny, J. M., \& Baron, J. N. (1997). Resources and relationships: Social networks and mobility in the workplace. American Sociological Review, 62(5), 673-693.

Ponterotto, J. G. (2005). Qualitative research in counseling psychology: A primer on research paradigms and philosophy of science. Journal of Counseling Psychology, 52(2), 126-136.

Prasad, (1993). Symbolic processes in the implementation of technological change: A symbolic interactionist study of work computerization. Academy of Management Journal, $36,1400-1429$.

Rhoades, G. (1983). Conflicting interests in higher education. American Journal of Education, 91(3), 283-327. 
Rhoades, G. (1987). Higher education in a consumer society. The Journal of Higher Education, $58(1), 1-24$.

Rhoades, G. (1996). Reorganizing the faculty workforce for flexibility: Part-time professional labor. Journal of Higher Education, 67(6), 626-59.

Rhoades, G. (2001). Managing productivity in an academic institution: rethinking the whom, which, what, and whose of productivity. Research in Higher Education, 42(5), 619-632.

Rhoades, G. (2005). Capitalism, academic style, and shared governance. Academe, 91(3), 38-42.

Rhoades, G. (2007). Technology-enhanced courses and a mode III organization of instructional work. Tertiary Education and Management, 13(1), 1-17.

Rhoades, G. (2012). Faculty engagement to enhance student attainment. Paper prepared for National Commission on Higher Education Attainment. Retrieved from http://www.acenet.edu

Rhoades, G., Kiyama, J., McCormick, R., \& Quiroz, M. (2008). Local cosmopolitans and cosmopolitan locals: New models of professionals in the academy. Review of Higher Education, 31(2), 209-235.

Rhoades, G., \& Slaughter, S. (1997). Academic capitalism, managed professionals, and supplyside higher education. Social Text, 15(2), 9-38.

Rhoades, G., \& Slaughter, S. (2004). Academic capitalism in the new economy: challenges and choices. American Academic, 1(1):37-60.

Rhoades, G., \& Sporn, B. (2002). New models of management and shifting modes and costs of production: Europe and the United States. Tertiary Education and Management, 8(1), 328.

Rhoads, R. A., Sayil Camacho, M., Toven-Lindsey, B., \& Berdan Lozano, J. (2015). The 
Massive Open Online Course movement, xMOOCs, and faculty labor. The Review of Higher Education, 38(3), 397-424.

Robertson, I. (2008). Sustainable e-learning, activity theory and professional development. In R. Atkinson \& C. McBeath (Eds.), Where are you in the landscape of educational technology? Proceedings of the 25th annual conference Australian society for computers in learning in tertiary education (Vol. 1, pp. 819-826). Melbourne, Australia: ASCILITE.

Robst, J. (2000). Do state appropriations influence cost efficiency in public higher education? Applied Economics Letters, 7, 715-719.

Rogers, E. M. (2003). The Diffusion of Innovations ( $5^{\text {th }}$ ed.). New York, NY: Free Press. Rostan, M. (2010). Challenges to academic freedom: some empirical evidence. European Review, 18(1): S71-S88.

Rovai, A., \& Downey, J. (2010). Why some distance education programs fail while others succeed in a global environment. Internet and Higher Education, 13(3), 141-147.

Ryan, G. W., \& Bernard, H. R. (2003). Techniques to identify themes. Field Methods, 15(85), 85-109.

Sandeen, C. A. (2014). Unbundling versus designing faculty roles (White paper). American Council on Education: Presidential Innovation Lab.

Santilli, S., \& Beck, V. (2005). Graduate faculty perceptions of online teaching. Quarterly Review of Distance Education, 6(2), 155-160. Retrieved from Academic Search Alumni Edition database.

Seo, M., \& Douglas, W.E. (2002). Institutional contradictions, praxis, and institutional change. The Academy of Management Review, 27(2), 222-247.

Shafritz, J. M., Ott, J. S., \& Jang, Y. S. (2011). Classics of organization theory (7th ed.). Boston, 
MA: Wadsworth Cengage Learning.

Slaughter, S., \& Rhoades, G. (2004). Academic capitalism and the new economy: Markets, state, and higher education. Baltimore, MD: The Johns Hopkins University Press.

Sloan Consortium (2013). Grade change: Tracking online education in the United States. Retrieved from http://sloanconsortium.org/publications/survey/grade-change-2013

Smith, V. C. (2008). The unbundling and rebundling of the faculty role in e-learning community college courses (Doctoral dissertation). ProQuest Dissertations and Theses (Accession Order No. AAT 3315310).

Snow, D. A. (2001). Extending and broadening Blumer's conceptualization of symbolic interactionism. Symbolic Interaction, 24/3, 367-377.

Stake, R. E. (1995). The art of case study research. Thousand Oaks, CA: Sage.

Steck, H. (2003). Corporatization of the university: Seeking conceptual clarity. Annals of the American Academy of Political and Social Science, 58(5), 66-83.

Strauss, A., \& Corbin, J. M. (1990). Basics of qualitative research: Grounded theory procedures and techniques. Thousand Oaks, CA: Sage.

Szekeres, J. (2004). The invisible workers. Journal of Higher Education Policy \& Management, 26(1), 7-22. doi:10.1080/1360080042000182500

Szekeres, J. (2006). General staff experiences in the corporate university. Journal of Higher Education Policy and Management, 28(2), 133-145. doi:10.1080/13600800600750962

Tabata, L. N., \& Johnsrud, L. K. (2008). The impact of faculty attitudes toward technology, Distance education and innovation. Research in Higher Education, 49(7), 625-646.

Tallent-Runnels, M. K., Thomas, J. A., Lan, W. Y., Cooper, S., Ahern, T. C., Shaw, S. M., \& 
Xiaoming Liu, X. (2006). Teaching courses online: a review of the research. Review of Educational Research, 76(1), 93-135.

Tracy, S.J. (2010). Qualitative quality: Eight ‘big-tent' criteria for excellent qualitative research. Qualitative Inquiry, 16(10) 837-851.

Trahar, S. (2011). Changing landscapes, shifting identities in higher education: narratives of academics in the UK. Research in Education, 86, 46-60.

Tuchman, G. (2009). Wannabe U: Inside the corporate university. Chicago, IL: University of Chicago Press.

University of Missouri. (2018). MU Facts. Retrieved from http://missouri.edu/about/facts

University of Missouri. (2018). Mission. Retrieved from

https://missouri.edu/about/mission

University of Missouri-Kansas City. (2018). Chancellor's Office. Retrieved from https://www.umkc.edu/chancellor/mission-vision.cfm

University of Missouri-Kansas City. (2018). Facts. Retrieved from https://www.umkc.edu/facts/

University of Missouri-Saint Louis. (2018). Mission. Retrieved from http://www.umsl.edu/proud/about/mission.html

University of Missouri-Saint Louis. (2018). UMSL By the Numbers. Retrieved from https://www.umsl.edu/proud/by-the-numbers.html

van der Werf, M., \& Sabatier, G. (2009). The College of 2020: Students. Retrieved from http://research.chronicle.com/asset/TheCollegeof2020ExecutiveSummary.pdf

Weerts, D. J., \& Ronca, J. M. (2012). Understanding differences in state support for higher 
education across states, sectors, and institutions: A longitudinal study. The Journal of Higher Education, 83(2), 155-185.

Wenger, E. (1998). Communities of practice: Learning, meaning, and identity. New York, NY: Cambridge University Press.

Weick, K. E. (1976). Educational organizations as loosely coupled systems. Administrative Science Quarterly, 21(1), 1-19.

Wertz, F., Charmaz, K., McMullen, L. M., Josselson, R., Anderson, R., \& McSpadden, E. (2011). Five ways of doing qualitative analysis. New York, NY: Guilford.

Whitchurch, C. (2012). Expanding the parameters of academia. Higher Education, 64(1): 99117.

Whitchurch, C., \& Gordon, G. (2010). Diversifying academic and professional identities in higher education: Some management challenges. Tertiary Education and Management $16(2), 129-144$

Wiesenberg, F., \& Stacey, E. (2005). Reflections on teaching and learning online: Quality program design, delivery and support issues from a cross-global perspective. Distance Education, 26(3): 385-404.

Williams, K. (2008). Troubling the concept of the 'academic profession' in the $21^{\text {st }}$ Century higher education. Higher Education, 56, 533-544. doi: 10.1007/s10734-007-9109-x

Williams van Rooij, S. (2011). Higher education sub-cultures and open source adoption. Computers \& Education, 57(1), 1171-1183.

Wilson, A. (2012). Effective professional development for e-learning: what do managers think? British Journal of Educational Technology, 43(6), 892-900. doi:10.1111/j.14678535.2011.01248.x 
Wolff, R. A. (2010, September/October). New roles, new rules for accreditation. Trusteeship, 18(5), 14-19.

Wood, D. (2013). The innovative university: Changing the DNA of higher education from the inside out by Clayton M. Christensen and Henry J. Eyring (review). The Review of Higher Education, 36(4), 570-571. doi: 10.1353/rhe.2013.0047

Worthen, H. (2002). Bargaining for 'quality' in higher education: a case study from the City Colleges of Chicago. Labor Studies Journal, 27(3), 1-23.

Ybema, S., Yanow, D., Wels, H., \& Kamsteeg, F. (2010). Ethnography. In A. Mills, G. Durepos, \& E. Wiebe (Eds.), Encyclopedia of case study research (pp. 348-352). Thousand Oaks, CA: SAGE. doi: http://dx.doi.org/10.4135/9781412957397.n129

Yick, A. G., Patrick, P., \& Costin, A. (2005). Navigating distance and traditional higher education: online faculty experiences. The International Review of Research in Open and Distance Learning, 6(2), 1-18.

Yin, R. K. (2009). Case study research: Design and methods ( ${ }^{\text {th }}$ ed). Thousands Oaks, CA: Sage.

Zott, C., \& Amit, R. (2010). Business model design: an activity system perspective. Long Range Planning, 43, 216-226. 


\section{VITA}

I have been involved in higher education for nearly 25 years and have worked in the curriculum and instructional design field that entire time. I am passionate about quality teaching and learning. My research agenda reflects that passion and the changing nature of how institutions are delivering courses, particularly online.

For over a decade, I worked in a central department on campus where I consulted with instructors from across campus, from every college, school, and discipline, providing me insights into what works, instructionally, in a variety of contexts. That opportunity was invaluable because I was able to share with instructors from across campus teaching strategies they may not have otherwise considered.

Later, my focus shifted more broadly to developing new undergraduate and graduate online and hybrid programs. Leveraging my years of experience gave me the chance to create learning opportunities for students that ensured the same rigorous standards applied to in-class learning. Especially now, during 2020 and the pandemic, this is more vital than ever.

Lastly, I have had the opportunity to pursue my own passion of teaching. For many years, I taught a graduate course on college teaching with technology. More recently, I taught undergraduate courses on professional development. Albeit very different student audiences, all these courses gave me the opportunity to "practice what I preach" and create great courses that emphasized student learning and success. 